NBER WORKING PAPER SERIES

THE COLLATERAL TRAP

Frédéric Boissay

Russell Cooper

Working Paper 20703

http://www.nber.org/papers/w20703

\author{
NATIONAL BUREAU OF ECONOMIC RESEARCH \\ 1050 Massachusetts Avenue \\ Cambridge, MA 02138 \\ November 2014
}

We thank seminar participants at CREI, Sciences-Po Paris, Pennsylvania State University, BIS, CSEF (Capri), and Zurich University for their comments. A special thanks to Elena Carletti, Ed Green, and Antoine Martin for comments and suggestions. A previous version of this paper circulated under the title "Inside and Outside Collateral: Implications for Financial Market Instability".The views expressed in this paper are those of the authors and do not necessarily reflect those of the ECB or the National Bureau of Economic Research.

NBER working papers are circulated for discussion and comment purposes. They have not been peer-reviewed or been subject to the review by the NBER Board of Directors that accompanies official NBER publications.

(C) 2014 by Frédéric Boissay and Russell Cooper. All rights reserved. Short sections of text, not to exceed two paragraphs, may be quoted without explicit permission provided that full credit, including $\odot$ notice, is given to the source. 
The Collateral Trap

Frédéric Boissay and Russell Cooper

NBER Working Paper No. 20703

November 2014, Revised March 2016

JEL No. E44,E51,G21,G23

\author{
Frédéric Boissay \\ European Central Bank \\ Kaiserstrasse 29, 60311 Frankfurt am main \\ Germany \\ frederic.boissay@ecb.europa.eu \\ Russell Cooper \\ Department of Economics \\ The Pennsylvania State University \\ 611 Kern \\ State College, PA 16802 \\ and NBER \\ russellcoop@gmail.com
}

ABSTRACT

Active wholesale financial markets help reallocate deposits across heterogeneous banks. Because of incentive problems these flows are constrained and collateral is needed. The composition of collateral matters. The use of inside assets (loans) creates a "collateral pyramid" in that cash flows from one loan can be pledged to secure another. Through collateral pyramids the financial sector creates safe assets, but at the cost of exposing the economy to systemic panics. Outside collateral (treasuries) serves as foundation of, and stabilises, the pyramid. There is a threshold for the volume of treasuries, below which investors panic and the pyramid collapses. 


\title{
The Collateral Trap
}

\author{
Frédéric Boissay* and Russell Cooper ${ }^{\dagger} \ddagger$ \\ This Version: March 1, 2016 \\ First Version: November 17, 2014
}

\begin{abstract}
Active wholesale financial markets help reallocate deposits across heterogeneous banks. Because of incentive problems these flows are constrained and collateral is needed. The composition of collateral matters. The use of inside assets (loans) creates a "collateral pyramid" in that cash flows from one loan can be pledged to secure another. Through collateral pyramids the financial sector creates safe assets, but at the cost of exposing the economy to systemic panics. Outside collateral (treasuries) serves as foundation of, and stabilises, the pyramid. There is a threshold for the volume of treasuries, below which investors panic and the pyramid collapses.
\end{abstract}

\section{Introduction}

This paper studies the fragility of wholesale financial markets. These markets facilitate the reallocation of funds within the banking sector: banks with relatively profitable opportunities borrow from other banks. These exchanges may include various market-financed transfers of assets between banks and take a variety of forms, including overnight funding markets, collateralised loan markets, etc. For short, we refer to those markets as "interbank loan" markets.

Markets secured by inside collateral are less stable. Our analysis highlights the significance of collateral for the functioning of the interbank markets. Both the volume, the value, and the composition of collateral matter. We make a distinction between "outside collateral", such as the pledging of treasuries in a repo arrangement, and "inside collateral", such as the

\footnotetext{
*Bank for International Settlements, frederic.boissay@bis.org

${ }^{\dagger}$ Department of Economics, The Pennsylvania State University; Research Associate, NBER, russellcoop@gmail.com

${ }^{\ddagger}$ We thank seminar participants at CREI, Sciences-Po Paris, Pennsylvania State University, BIS, CSEF (Capri), and Zurich University for their comments. A special thanks to Elena Carletti, Ed Green, and Antoine Martin for comments and suggestions. The views expressed in this paper are those of the authors and do not necessarily reflect those of the BIS.
} 
pledging of cash flows in the asset backed commercial paper market 1 We argue that markets are, all else equal, less stable when they are secured by inside collateral than when they are secured by outside collateral. The use of inside assets creates a type of "collateral pyramid" in that cash flows from one loan can be pledged to secure another. Through collateral pyramids, the financial sector is able to create safe assets, but at the cost of exposing the economy to systemic panics. Indeed, the process of creation of safe assets by banks, which is endogenous, is subject to strategic complementarities.

Strategic complementarities. Reflecting incentive problems in the interbank market, a bank's collateral determines its ability to borrow and thus the extent of the reallocation of savings from low to high quality banks. In equilibrium, the pledgeability of borrowers' cash flows itself depends, through adverse selection, on borrowers' quality. If lenders believe that borrowers are high quality, then borrowing constraints are lax, the demand for funding and the equilibrium interbank rate are high. Only high quality banks, those whose projects have a positive net present value (NPV), borrow funds. So, borrowers are indeed high quality. Those complementarities are magnified when transactions are collateralised. Indeed, high quality loans have high collateral value, which further relaxes borrowing constraints, raises demand, the equilibrium rate, and borrower quality.

Yet, for the same parameter values there may exist a "collateral trap" in which lenders are pessimistic about the quality of borrowers. In this equilibrium, borrowing constraints are tight, borrowers demand little funding, and the equilibrium rate is low. As a consequence, most projects have positive NPV, even low quality banks borrow, and the sorting of borrowers is less efficient. The lack of information about borrowers' cash flows undermines their pledgeability. In a collateral trap, pledgeability is low and the volume of safe assets that borrowers can engineer out of their cash flows, i.e. inside collateral, is scaled down, which contributes to tightening the borrowing constraint.

The resulting complementarity may generate multiple equilibria including a collateral trap, characterized by (i) a reduction in the creation of inside collateral by banks, (ii) reduced interbank activity, (iii) resource mis-allocation, (iv) a recession.

Treasuries as foundation of the collateral pyramid. We provide a crisp characterization of the conditions on the economy's fundamentals for this type of multiplicity. We emphasize the specific role of outside collateral, like treasuries, in avoiding the collateral trap. Treasuries serve as the foundation of the collateral pyramid. A larger foundation contributes to making the pyramid immune to beliefs, more stable. There is a threshold for the volume of treasuries

\footnotetext{
${ }^{1}$ While the terminology is reminiscent of the distinction between private and public liquidity in Holmstrom and Tirole (1998), our focus is on different forms of collateral as pledgeable assets rather than liquidity per se. In our model, as in theirs, a complementarity emerges between inside and outside collateral. Note also that treasuries may not necessarily be the only type of outside collateral or even may not always be considered as outside collateral, as would for example be the case when a sovereign issues debt in order to bail out its domestic banking sector.
} 
held by the banking sector, below which investors may panic and the pyramid collapse.

Link to the literature. Models of fragility provide a framework for understanding the power of expectations in driving outcomes in financial markets. Our model of strategic uncertainty in financial markets focuses on loans between financial entities, and on the characteristics of the assets used to secure those loans. It purposefully downplays the role of financial instability stemming from bank runs along the lines of Diamond and Dybvig (1983) 2 Indeed, capital flow reversals and "sudden stops" are not key elements in our analysis 3 As in Kiyotaki and Moore (1997) and the literature that follows, collateral is central to our analysis as a means of coping with incentive problems. This literature focuses on the effects of endogenous variations in collateral value. In contrast, we emphasize how endogenous variations in the composition of collateral, i.e. the relative magnitudes of inside and outside collateral, determine the ability of banks to borrow against their assets. This is reflected, in part, by the height of the equilibrium determined collateral pyramid. The complementarity between the two types of collateral in our model stands in contrast with Krishnamurthy and Vissing-Jorgensen (2015). In their model, banks provide safe assets to households and the rise in the supply of treasuries crowds out banks deposits via effects on the equilibrium price of treasuries. In contrast, we focus on the holdings of treasuries by collateral constrained banks and on the role of such securities in securing banks' wholesale funding. As Krishnamurthy and Vissing-Jorgensen (2015), we too predict that following an increase in treasury supply the yield spread between risky loans and safe assets should go down (see also Krishnamurthy and Vissing-Jorgensen (2012)). But in our case the reduced spread reflects the lower shadow collateral value of safe assets for banks, not a deterioration of the non-pecuniary services of safe assets for households.

In Benmelech and Bergman (2012) a higher value of collateral leads to more lending. Further, they assume that the value of collateral depends positively on the liquidity constraints of firms who would be the natural purchasers of the collateral in the event of default. This generates a complementarity between collateral values and lending. Benmelech and Bergman (2012) discuss the types of equilibria that can arise, including one they term a "credit trap" in which collateral values and lending are low and injections of liquidity do not increase lending. In the collateral trap banks too are led to invest deposits in a relatively low return activity because the return on the interbank market is driven to a low value through adverse selection. In this sense, liquidity is hoarded rather than lent to more productive activities, as in a credit trap. A distinguishing

\footnotetext{
${ }^{2}$ See, for example, Krishnamurthy, Nagel, and Orlov (2014), Gorton and Metrick (2012), Covitz, Liang, and Suarez (2009), Copeland, Martin, and Walker (2011), Acharya and Schnabl (2010), and Fleming, Hrung, and Keane (2010) for arguments supporting this emphasis. Moreover, the runs observed on asset-backed commercial paper (ABCP) markets in 2007-8 were different from the traditional deposit-based bank runs, which Gorton (1988) showed to be mainly related to economic fundamentals. In particular, Covitz, Liang, and Suarez (2009) find that investors in ACBP markets ran from all types of programs, even from those with apparently solid fundamentals.

${ }^{3}$ As emphasized by Caballero (2009), the financial crisis in the US was not marked by a sudden withdrawal of external funds.
} 
feature of our model is the collapse of interbank market transactions, particularly those backed by inside collateral. Indeed, consistent with evidence we present, our analysis highlights that the interbank loans backed by inside assets are much less resilient than those backed by outside assets. The collateral trap is also distinct from the traditional Keynesian liquidity trap and from Caballero and Fahri (2015)'s "safety trap". In those traps, the excess demand for liquidity or safe assets leads to a recession when the nominal interest rate hits the zero lower bound. Also, like Benmelech and Bergman (2012), the focus is on the anemic effects of monetary policy post crisis. In our model, in contrast, a recession results from the collapse of the interbank market and is associated with an inefficient allocation of resources. Moreover, the economy falls into the collateral trap when interest rates are low, not necessarily when they are at the zero lower bound.

Link to facts and policy implications. Switches from optimism to pessimism resemble the observed collapse in wholesale funding markets during the Great Recession. The predictions of our model relate to both financial flows and real activity and are consistent with several observations during the recent financial crisis. For example, our model predicts the excess volatility of the Asset Backed Commercial Paper (ABCP) relative to repo markets. Our model creates comparable variations in the use of inside and outside collateral. The implications of the model for output and capital reallocation also relate to the evidence presented in Foster, Grim, and Haltiwanger (2013) on factor reallocation. They argue that, in contrast to previous periods of low economic activity, the Great Recession did not correspond to a period of increased reallocation of factors of production.

Though the paper is not intended as a basis for assessing the full costs and benefits of policy analysis, it is possible to consider some crude forms of interventions within our framework, for example restrictions on bank portfolios, the setup of a central bank deposit facility, bank subsidies, or collateral swaps. A key finding is that asset portfolio restrictions are costly insofar as they limit reallocation through the interbank market. This restriction may eliminate the fragility of these markets but they do so by supporting a unique equilibrium with low interbank flows. We also find that bank subsidies, the setup of a central bank deposit facility, and collateral swaps, contribute to the stability of the financial sector. The paper proceeds as follows. Section 2 documents the evolution of secured funding markets in the US around the recent financial crisis. Section 3 describes our theoretical framework and Section 4 describes the conditions under which financial markets may collapse. The implications of those events are analysed in Section 5. Section 6 explores to the link between our model and the facts, and Section 7 discusses the potential policy interventions that influence both the multiplicity of equilibria as well as the efficiency of the interbank markets. The last section concludes. 


\section{Facts}

This section presents some pertinent facts related to the flows of funds and rates in interbank markets in the US before and during the 2007-8 financial crisis. These observations are used initially as motivation. Later, we comment those facts again, through the lenses of our model. Fact \# 1: The 2007-8 crisis occurred after a historical increase in bank deposits and a historical fall in US treasuries holdings by the US financial sector.

Figure 1 shows the long term evolution of the volume of treasuries held by the US financial sector and the rest of the world, against the evolution of US household deposits. Treasuries and deposits both increased from 1970 until 1995. After 1995, the growth of deposits and of the demand for treasuries by the rest of the world accelerated, while US banks reduced their holding of treasuries; until the start of the crisis. At that time, banks deposits were at a historical high, and treasuries held by the financial sector were at a historical low, reflecting a "crowding out effect" and the shortage of safe assets in the US financial sector (Caballero (2009)). In 2007q2, notably, only $2.5 \%$ of the funds deposited in US banks were invested into treasuries. This suggests that, at that time, the rate of transformation of risky assets into safe deposits by US banks was unusually high.

Figure 1: US treasuries held by the financial sector and household deposits

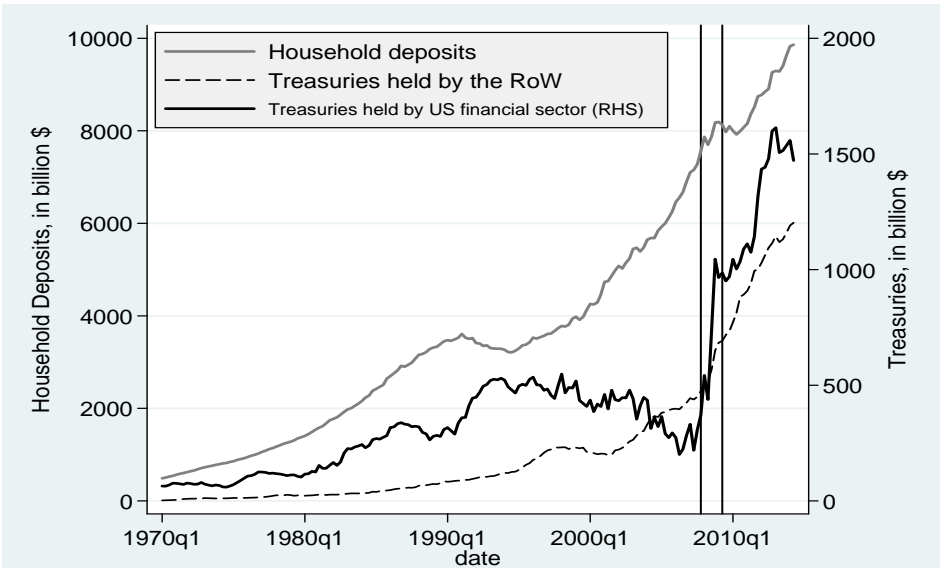

Note: Total outstanding amount of US treasuries securities held by the US financial sector: Source: US Flows of Funds Accounts (Table L.209, series FL763061100.Q + FL753061103.Q + FL743061103.Q + FL633061105.Q + FL653061105.Q + FL663061105.Q). Household Deposits: total currency and deposits (including money market fund shares) by households and nonprofit organizations; Source: US Flows of Funds (Table L.100, series FL154000025.Q). Treasuries held by the Rest of the World: Source: US Flows of Funds Accounts (Table L.209, series FL263061105.Q). Vertical lines: Great Recession's troughs and peaks (NBER dates).

Fact \# 2: During the 2007-8 crisis, Asset Backed Commercial Paper (ABCP) markets collapsed as a substantial number of Special Purpose Vehicles experienced a run. In contrast, the markets secured by treasuries or government guaranteed assets remained stable.

Fact \#2 has been documented in a number of papers. For example, Copeland, Martin, and Walker (2011) show that the segments of the US repo market, such as tri-party repos and the bilateral repos, which represent more than two thirds of the US repo market, remained 
Figure 2: Volume of Secured Loans, as a ratio to Households' Deposits

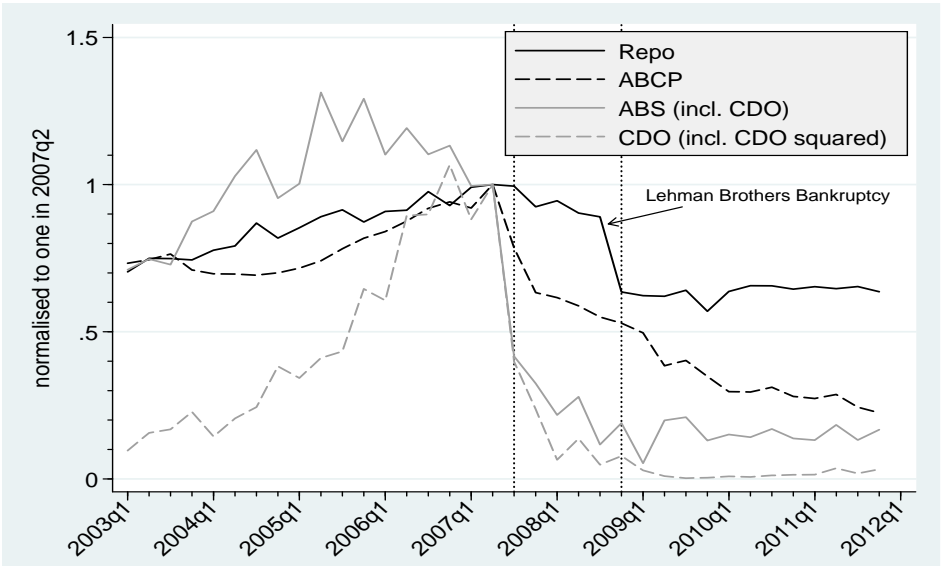

Note: Volumes of repos, ABCP, and ABS, divided by households deposits; the ratio is normalised to 1 in 2007q2. Repo and Fed Funds volumes: outstanding amounts borrowed by the financial sector (excluding foreign banks offices); Source: US Flows of Funds (Table L.207, series FL892150005.Q). ABCP: outstanding amounts; Source: Federal Reserve Bank of St Louis (FRED) database (series DTBSPCKAM). ABS and CDO: quarterly issuances; Source: Asset Backed Alert and Dealogic. Household Deposits: total currency and deposits (including money market fund shares) by households and nonprofit organizations; Source: US Flows of Funds (Table L.100, series FL154000025.Q). Vertical lines: Great Recession's troughs and peaks (NBER dates).

strikingly stable during the crisis. Overall, the reduction in repo transactions was rather limited and dwarfed by the reduction in $\mathrm{ABCP}$ transactions. In practice, $\mathrm{ABCP}$ transactions are operated through so-called Special Purpose Vehicles (SPVs), which are essentially subsidiaries bankruptcy-remote from their parent banks that issue commercial paper and use the proceeds to invest in assets like mortgages or corporate loans (see, e.g., Gorton and Souleles (2005)) ${ }^{4}$ By mid-2007, this type of funding was prominent in the US, as SPVs totalled assets over $\$ 1.3$ trillion, compared to broker-dealer repos of $\$ 2.5$ trillion, and financial commercial paper of $\$ 0.8$ trillion. But it also turned out to be most unstable. Covitz, Liang, and Suarez (2009) document a significant fall in the number of SPVs at the onset of the crisis, with about $40 \%$ of those SPVs facing in a run. In Figure 2 we compare the evolution of wholesale funding markets secured by outside collateral (repos) or inside collateral (ABCP, and Asset Backed Securities - ABS) during the recent financial crisis 5 The upshot is that the markets secured by inside collateral were less stable than those secured by outside collateral. In the run-up to the crisis, the three markets essentially evolved together, and their size increased. When in Summer 2007 the crisis hit, the volume of transactions fell by $60 \%$ in the ABS market and by $40 \%$ in the ABCP market, while it fell by less than $10 \%$ in the repo market, which confirms the resilience of the latter documented in earlier work.

\footnotetext{
${ }^{4}$ Bankruptcy-remoteness is a central element to the use and creation of collateral and, accordingly, will also be an important aspect of our analysis.

${ }^{5}$ ABSs are securities whose income payments is derived from and "backed" by a specified pool of assets, like mortgages, credit card loans etc, which cannot be sold individually. Collateralized Debt Obligations (CDO) are structured financial products that pools together cash flow-generating assets and repackage those assets into discrete tranches that can be sold to investors. The maturity ABSs and CDOs is usually longer (above eighteen months) than that of repos and ABCPs, which does not exceed a quarter (overnight for the repos and less than six weeks for $\mathrm{ABCPs}$ ). To compare the evolution of those markets, we report the quarterly issuances of $\mathrm{ABS}$ and CDOs together with the outstanding volumes (end-of-quarter) of repos and ABCPs.
} 
Fact \# 3: During the crisis the Fed fund rate and the yields on repos and three-month treasuries fell sharply but the spreads between those yields remained close to zero. In contrast, the spread between corporate loan rates rose abruptly.

Figure 3 shows that the repo rate has been essentially the same as the risk-free Federal Fund and three month treasury rates. Those rates increased together in the run-up to the crisis, and then plummeted from $5.25 \%$ in $2007 \mathrm{q} 2$ to about $0.25 \%$ in $2009 \mathrm{q} 1$. The figure also shows that the spread between the average corporate loan rate (dashed black line) and the Federal Fund rate (plain black line) increased significantly during the crisis. This spread will play an important role in our analysis; we will argue that its increase during the crisis is indicative of the impairment of the financial intermediation process.

Figure 3: Nominal Interest Rates by Asset Classes

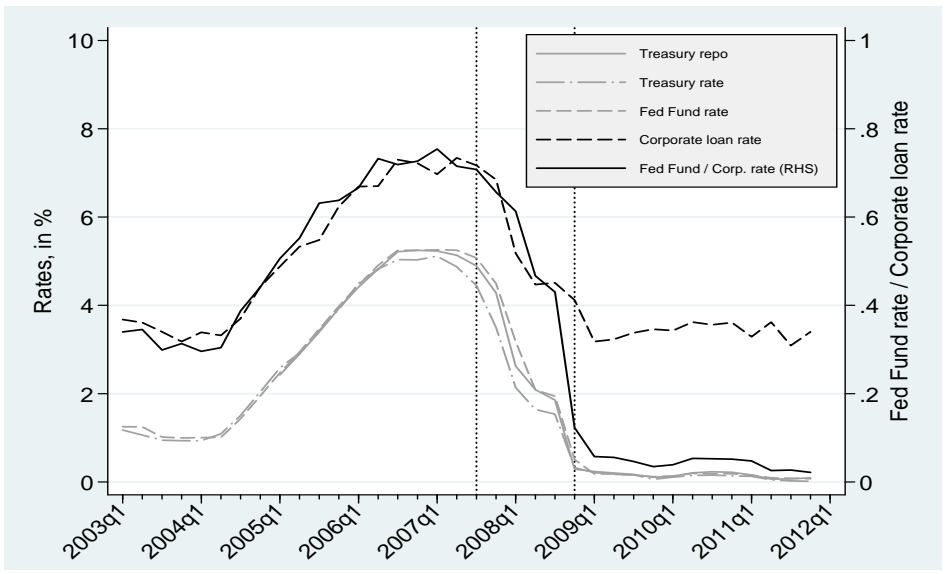

Note: Quarterly averages. Repo rates are the DTCC GCF Repo Index of the interest rates paid for the most-traded GCF Repo contracts on US treasury securities, federal agency securities, and mortgage-backed securities (MBS) issued by Fannie Mae and Freddie Mac; Source: DTCC. The treasury rate is the interest rate on the 3-month treasury securities (constant maturity); Source: Federal Reserve Bank of St Louis FRED database. The corporate loan rate is the average of commercial and industrial loan rates ; Source: Federal Reserve Board Survey of Terms of Business Lending. Vertical lines: Great Recession's troughs and peaks (NBER dates).

\section{Environment}

We consider an economy populated by a government, a representative household, and banks. All agents live one period $\sqrt[6]{6}$ We present their choice problems and constraints in turn.

\subsection{Government}

The government finances expenditures $\mathbf{b}$ by borrowing from banks at rate $r^{b}$, and repays debt by raising taxes of $\mathbf{b} r^{b}$ on households at the end of the period. This budget constraint is built into the consumption of the representative household in (1). Though public expenditures have no direct benefit, the debt will have indirect social value through its use as collateral by banks.

\footnotetext{
${ }^{6}$ The model is static as the interactions take place just once. Note though that there are two stages to these interactions.
} 


\subsection{Household}

The representative household saves $s$ units of the single good through deposits into banks at the beginning of the period. At the end of the period the household consumes the return on deposits, $s r^{d}$, minus the taxes $\mathbf{b} r^{b} \bigcup^{7}$ For simplicity, assume linear utility over consumption, $c$ :

$$
u(c)=c=s r^{d}-\mathbf{b} r^{b} .
$$

\subsection{Banks}

There is a continuum of mass one of banks collecting deposits $s$ from the household. Each bank has access to a continuum of fixed size projects as well as to a storage technology. There are two stages of bank investments. In the first stage, banks are identical and use deposits to purchase government bonds, $b$, setting the remainder, $s-b$, aside for second stage investments. In the second stage, banks learn their productivity, $\varepsilon$, and become heterogenous. They can then invest into their projects, or lend to more productive banks on an interbank market. The interbank market arises endogenously to allow banks to reallocate their funds once they have learned their productivity. In the second stage, banks may also store goods. We focus on a situation where banks operate new projects through subsidiaries created specifically for this purpose. Those subsidiaries have limited liability, in the sense that their parent banks can collect their profits but have no legal ownership. In essence, they resemble the bankruptcy-remote SPVs, which banks set up in practice to raise funds on collateralized debt markets (Acharya, Schnabl, and Suarez (2013)). Through this structure, banks are able to use cash flows from one subsidiarily as collateral for a loan to another subsidiary when protecting assets in a bankruptcy proceeding. We first study the choices of the bank in the second stage. Using these, we formulate the optimization problem of the bank in the first stage.

\subsubsection{Stage 2 Choices: Interbank Market Participation}

In the second stage banks, after making a portfolio choice in the first stage, learn their productivity $\varepsilon$. The size of each project is normalised to one. The projects of bank with productivity $\varepsilon$ (for short, bank $\varepsilon$ ) yields gross unit return $\varepsilon a$. The $\varepsilon$ s are distributed over $[0,1]$ with a continuously differentiable cumulative distribution function $G(\varepsilon), \forall \varepsilon \in[0,1]$. Once the $\varepsilon$ 's are drawn, banks allocate their available funds, $s-b$, into interbank loans or their own projects in order to maximize profit. Let $r$ be the interbank loan rate. Then, there is a critical productivity level, denoted $\bar{\varepsilon}$, with

$$
\bar{\varepsilon}=r / a,
$$

\footnotetext{
${ }^{7}$ In the model, there will be no friction between banks and households. Therefore, there will be no material distinction between bank deposits and bank equity, and $r^{d}$ may be equally interpreted as the return on deposits plus dividends.
} 
such that a bank with $\varepsilon=\bar{\varepsilon}$ is indifferent between undertaking projects and lending on the interbank market. Banks with $\varepsilon<\bar{\varepsilon}$ lend on the interbank market; those with $\varepsilon \geq \bar{\varepsilon}$ borrow, as for them the net marginal return on investment is positive. To fix ideas, we will refer to those banks as "lenders" and "borrowers", respectively. As noted, our banks operate through subsidiaries, and the creditors of a given subsidiary have no claim on the cash flows generated by other subsidiaries within the parent bank. This is formalized by Assumption 1 on bankruptcy remoteness. Importantly, this assumption does not preclude the pledging of cash flow as collateral; on the contrary, as made clear below, this structure creates a role for collateralized lending and the engineering of safe assets by banks. BCBS (2009) lists a series of reasons why banks operate through bankruptcy-remote SPVs. Those include, inter alia, regulatory arbitrage, accounting (as the bank may move assets off its balance sheet), the revenues from the commission fees associated with the creation of SPVs. Acharya, Schnabl, and Suarez (2013) argue that regulatory arbitrage is the main motive. For the purpose of our paper, we abstract from those reasons and take banks' modus operandi as given 8 To fix ideas, we will refer to the subsidiaries of bank $\varepsilon$ as subsidiaries $\varepsilon$.

Assumption 1. (Bankruptcy Remoteness) Banks invest into projects through bankruptcyremote subsidiaries.

Apart from their projects, banks can also store goods, which generates a return $\gamma a$, with $\gamma<1$. In the discussion that follows, we proceed under the assumption that the storage technology is (weakly) inefficient, i.e. banks (weakly) prefer to either initiate projects or lend to other banks rather than undertake storage (see Assumption 5). The potential to store goods will nonetheless matter for the equilibrium outcome through its effects on borrowers' incentives. As it allows funds to be channelled to the most productive projects, the interbank market improves the efficiency of the financial sector. The higher $\bar{\varepsilon}$, the more productive are the banks operating projects, and thus the more efficient is the banking sector. Accordingly, we will interpret $\bar{\varepsilon}$ as a measure of financial efficiency. Clearly, in a frictionless world, only the most productive bank would operate its project: $\bar{\varepsilon}$ would be equal to one. However, there is a limit, determined in equilibrium, on how much productive banks (those with $\varepsilon \geq \bar{\varepsilon}$ ) can borrow on the interbank market. This limit takes into account the presence of two frictions: asymmetric information and moral hazard.

Assumption 2. (Asymmetric Information) Its realized value of $\varepsilon$ is known only to the bank.

Asymmetric information arises from the assumption that $\varepsilon$ is known to bank $\varepsilon$ only, and is not verifiable ex post. Thus, in equilibrium lenders will be able to compute the expected value

\footnotetext{
${ }^{8}$ In Appendix 9.4 we show that, without Assumption 1 the default and the subsequent bankruptcy of a subsidiary would endanger a bank's entire portfolio of assets, and might discipline the subsidiaries of the bank.
} 
of $\varepsilon$ for borrowers but contracts cannot be conditioned on bank specific variables.

Assumption 3. (Moral Hazard) The cash flows generated from storage are not seizable. Once it obtains a loan, a bank subsidiary can unilaterally decide to invest in storage.

Once a subsidiary obtains a loan, it has a choice to invest the funds in a project, or to invest them in storage. Under Assumption 3, the returns from storage cannot be seized by the lenders, which gives the subsidiary the option to abscond and default on the loan. Since the parent bank is not liable for the subsidiary's loan (Assumption 1), the subsidiary cannot commit itself to invest in the project and repay the loan. This creates a moral hazard problem, which will be important for determining an equilibrium restriction on the amount borrowed. To deal with the subsidiary's incentive issues, lenders can restrict borrowing and require the subsidiary to pledge assets as collateral. As it meets potential lenders, the subsidiary does not hold any assets. But it may pledge some of the assets of the bank it belongs to: indeed, the parent bank may have two different types of assets on its balance sheet. First, there are the government bonds purchased in stage $1, b$ (determined later in Section 3.3.2). Those bonds are publicly traded, easy to resell or liquidate, and therefore can be seized at no cost by the lenders. Hence, lenders would accept them as collateral, with no haircut. Second, there may be projects, which the bank funded in the past through other subsidiaries. Unlike government bonds, lenders cannot seize the entire cash flows of those projects, though. We assume that they can seize only a fraction $\theta$ of them, and that the remainder, the fraction $1-\theta$, can be retained by the parent bank. As in Tirole (2006), one could interpret those retained cash flows as reflecting the private benefits that the bank is able to extract from the projects. They could also reflect lenders' lack of information, knowledge, and expertise about those projects, which prevents lenders from seizing all the proceeds. Admittedly, in practice, lenders collect a lot of information on the projects they finance and the borrower should not be able to hide anything. But the assumption here is that they cannot seize all the cash flows generated by the other subsidiaries within their borrower's parent banking group. Else, lenders do have free and full access to the cash flows generated by the projects they finance. Finally, we assume that, to claim the collateral, lenders must beforehand pay a fixed cost, $f$. This fixed cost captures all the transaction costs that are related to the transfer of ownership of the projects but unrelated to the size of the default. For example, it may reflect court costs, the cost of a collective action against the parent bank, or the cost related to the lenders having to administer the projects themselves. To fix ideas, we interpret $f$ as the cost of setting up a "bad bank" that takes over the projects on behalf of the lenders. This fixed cost is shared among all the lenders defaulted upon $\sqrt[9]{9}$

\footnotetext{
${ }^{9}$ As there are potentially many lenders, we assume that they cooperatively share the costs and gains of post default actions.
} 
To recap: banks borrow through subsidiaries. Subsidiaries can secure the loans with two types of assets: government bonds and the cash flows of existing projects. Upon default, lenders can keep the full amount of the government bonds pledged; but they can only seize up to a fraction $\theta$ of the cash flows of the projects upon the payment of $f$. Throughout, government bonds are considered outside collateral while cash flows are termed inside collateral.

Interbank Trades. Under Assumption 3, a bank subsidiary can obtain a loan, invest the funds in storage, run away, and default. Its incentive to do this decreases with the value of its collateral but increases with the size of the loan. As a consequence, to prevent default, lenders take care never to allow the size of the loan to exceed a certain threshold that increases with the collateral value. As we explain below, a bank with $\varepsilon \geq \bar{\varepsilon}$ raises interbank funds in multiple stages, though multiple subsidiaries.

Initially, based upon its ex ante portfolio decision (i.e. the choice of $b$ ), the bank only holds government bonds. So, its subsidiaries can only secure loans with those bonds. Let $\phi^{b} s$ be the amount of those loans. Then, the incentive constraint that prevents the subsidiary of bank $\varepsilon$ from borrowing funds and absconding is:

$$
\gamma a\left(s-b+\phi^{b} s\right) \leq b r^{b}+\varepsilon a\left(s-b+\phi^{b} s\right)-\phi^{b} s r .
$$

The left side is the payoff from absconding. If the subsidiary invests in storage and runs away, its parent bank gets $\gamma a\left(s-b+\phi^{b} s\right)$. But the returns on the pledged government bonds, $b r^{b}$, are lost, as the lender has direct control over the government bonds pledged. By contrast, if the subsidiary does not run away, then its bank earns the return on government bonds plus the return on the project, $\varepsilon a\left(s-b+\phi^{b} s\right)$, net of the interbank loan repayment, $\phi^{b} s r$. This is indicated by the three terms on the right side of (3) 10

This incentive constraint must hold for all banks who borrow, i.e. for all $\varepsilon \geq \bar{\varepsilon}$. Hence, it must hold for the marginal bank's subsidiaries $\bar{\varepsilon}$. For subsidiaries $\bar{\varepsilon}$ the net return from not running away is independent of $\phi^{b}$, whereas the net return of running away increases with $\phi^{b}$. As a result, in equilibrium, (3) binds at $\varepsilon=\bar{\varepsilon}$, which yields (using (2)):

$$
\phi^{b}=\left(b\left(r^{b}-r\right) / s+\bar{\varepsilon} a\right) /(\gamma a)-1+b / s
$$

Building on these first projects, bank $\varepsilon$ can raise additional funds in order to finance more projects. It can setup new subsidiaries that issue new loans backed by the cash flows of the initial

\footnotetext{
${ }^{10}$ In this analysis, the subsidiary does not incorporate any effects its action might have on the operation of the parent bank. That is, the subsidiary maximizes its own profit. Alternatively, the subsidiary might take into account that by running away it deprives its parent bank of projects whose seizable cash flows could potentially be used at a later stage to raise additional funds, say $\Delta$, and generate more returns. For bank $\varepsilon$, every additional funding $\Delta$ yields $\Delta(\varepsilon a-r)$ as net return. This extra opportunity cost of investing into storage could be reflected in an additional term on the right side of (3). However, for the marginal bank, $\bar{\varepsilon}$, this opportunity cost is, by definition, zero. Hence this internalization does not alter incentives.
} 
projects. Importantly, those cash flows are all that the subsidiaries can pledge as collateral, as the government bonds have already been pledged to the first stage lenders. So, no asset is being pledged multiple times. Moreover, whether or not the first stage subsidiaries invested into their projects need not be observable to lenders for the latter to accept cash flows as collateral, since (3) ensures that no wealth is stored. (In this respect, it is sufficient that lenders observe that a loan $\phi^{b} s$ was made.) Let $\phi^{c(1)} s$ be the new funding that new subsidiaries $\varepsilon$ raise against the cash flow coming from the first stage project. The incentive constraint that prevents the subsidiaries from investing those funds in storage and absconding is:

$$
\begin{aligned}
& \gamma a \phi^{c(1)} s+b r^{b}+(1-\theta) \varepsilon a\left(s-b+\phi^{b} s\right)-\phi^{b} s r \\
& \leq b r^{b}+\varepsilon a\left(s-b+\phi^{b} s\right)-\phi^{b} s r+\phi^{c(1)} s(\varepsilon a-r)
\end{aligned}
$$

The left side is the total profit of the parent bank if its new subsidiaries store $\phi^{c(1)} s$ and default. The bank gets the return from storage, $\gamma a \phi^{c(1)} s$, but must forgo the fraction $\theta$ of the cash flows from the initial projects, which the defaulting subsidiaries pledged as collateral, $\theta \varepsilon a\left(s-b+\phi^{b} s\right)$. The default does not affect the rest of the bank beyond that (Assumption 1). So, the bank also gets the returns on government bonds, $b r^{b}$, and the unpledged cash flows from the first stage subsidiaries, $(1-\theta) \varepsilon a\left(s-b+\phi^{b} s\right)$, net of the payment of those subsidiaries' interbank loans, $\phi^{b} s r{ }^{11}$ Hence the expression on the left hand side. If, in contrast, the subsidiaries invest $\phi^{c(1)} s$ into new projects, then the bank earns the returns on government bonds and on the projects, net of the interests on interbank loans. This is indicated by the four terms on the right hand side. The incentive compatibility condition (5) simplifies to:

$$
\gamma a \phi^{c(1)}-\theta \varepsilon a\left(1-b / s+\phi^{b}\right) \leq \phi^{c}(\varepsilon a-r)
$$

Again, this condition holds with equality for the marginal bank's subsidiaries. Using (2), (6) becomes

$$
\phi^{c(1)}=(\theta \bar{\varepsilon} / \gamma)\left(1-b / s+\phi^{b}\right)
$$

The term $\theta \bar{\varepsilon} / \gamma$ is the fraction of the project that can be pledged as collateral in subsequent wholesale funding transactions. Under Assumption 4 (see below), it is smaller than one.

There is no reason for the process to stop. Indeed, once they obtain $\phi^{c(1)} s$, the subsidiaries invest into new projects, which new subsidiaries of the parent bank can use to secure new loans, $\phi^{c(2)}$, and finance new projects. In this way, the use of cash flows as collateral gives rise to

\footnotetext{
${ }^{11}$ One can show easily that, under Assumption 4 , in equilibrium (i.e. using (2), (4), and (12), one has $\phi^{b} s r<b r^{b}+(1-\theta) \bar{\varepsilon} a\left(s-b+\phi^{b} s\right)$, which means that the first stage subsidiaries of the marginal bank $\bar{\varepsilon}$ always pay their interbank loans. One can also show that, if $b / s$ is large enough, then one has $\phi^{b} s r>(1-\theta) \bar{\varepsilon} a\left(s-b+\phi^{b} s\right)$, which means that the first stage subsidiaries rely on the cash flows from their government bonds to pay back $\phi^{b} s r$.
} 
a sequence of new collateralised loans and collateral creation inside the banking sector. This is why we refer to cash flows as "inside" collateral. Specifically, let $\phi^{c(n)} s$ be the funds that subsidiaries $\varepsilon$ can raise against the cash flows of the projects financed at the $(n-1)^{\text {th }}$ round. Then, the corresponding $n^{\text {th }}$ incentive constraint is (for $n \geq 2$ )

$$
\gamma a \phi^{c(n)}-\theta \varepsilon a \phi^{c(n-1)} \leq \phi^{c}(\varepsilon a-r)
$$

and must again hold for all $\varepsilon \geq \bar{\varepsilon} \cdot 12$ In equilibrium, using the fact that (8) binds at $\varepsilon=\bar{\varepsilon}$, one gets (for all $n \geq 2$ )

$$
\phi^{c(n)}=(\theta \bar{\varepsilon} / \gamma) \phi^{c(n-1)} .
$$

It is useful to return to the role of Assumption 1. Cash flow can be pledged across subsidiaries in the same way that government bonds can be posted as collateral. In the event of default, the assets are retrieved by the lenders and the defaulting borrower is unable to protect these pledged assets. But, under Assumption 1, the other assets of the bank are protected during bankruptcy. Thus there is a clear distinction between the use of assets as collateral and their vulnerability under bankruptcy.

This process of loan creation is limited by the fixed cost $f$, motivated earlier as a cost of a court proceeding due to default. Lenders jointly pay this cost whenever their loans (here the $n^{\text {th }}$ loans) are defaulted upon. The lenders' threat to take over those assets, which is crucial in preventing the borrower from absconding, is credible only if the cash flows recovered by the lenders cover the fixed cost, though. It follows that a subsidiary can issue the $n^{\text {th }}$ interbank loan only if:

$$
\theta \bar{\varepsilon} a \phi^{c(n-1)} s \geq f
$$

The left side of 10 is the cash flows of the marginal borrowers (with $\bar{\varepsilon}$ ), which the new creditors can seize if those borrowers default on their loans. The constraint thus means that lenders must be in the position to claim the cash flows of the defaulting subsidiaries, e.g. be able to set up a bad bank, even for the least productive projects, $\bar{\varepsilon}$. The constraint 110 determines the maximum number of lending rounds, $N$.

Collateral Pyramid. The multiple rounds of lending described above form a "collateral pyramid"; see Figure 4. Those rounds arise endogenously, as the banks accumulate pledgeable assets through their subsidiaries. The foundation of the collateral pyramid (in gray in the figure) is made of assets created outside the financial sector, i.e. government bonds. The rest of the pyramid is made of collateral created inside the financial sector along the various lending rounds.

\footnotetext{
${ }^{12}$ Because they depend on $\varepsilon$, borrowers' cash flows, $\varepsilon a \phi^{c(n-1)} s$, are information sensitive, subject to the asymmetric information problem, and cannot be pledged as collateral (see Gorton and Ordonez (2014)). Only a fraction of it, $\theta \bar{\varepsilon} a \phi^{c(n-1)} s$ can be repackaged into information insensitive assets. This information insensitive fraction of the cash flows can be seen as the "senior" tranche of the subsidiaries's cash flows.
} 
The size of the pyramid corresponds to the total volume of safe assets that can be pledged as collateral in interbank transactions. It is limited by three main factors. First, it depends on the volume of government bonds held by banks relative to their deposits, $b / s$ : all things equal, the larger this collateral base, the bigger the pyramid. Thus, inside collateral builds upon outside collateral. Second, it also depends on the size of the fixed cost relative to the size of the banking sector, $f / s$ : all things being equal, the smaller the fixed cost, the "taller" the pyramid, and the more inside collateral. Third, the volume of safe assets in the economy depends on the degree of pledgeability of the banks' cash flows, $\theta \bar{\varepsilon} / \gamma$.

The degree of pledgeability (and notably paramater $\theta$ ) plays a critical role in our analysis. It determines how much inside collateral can be generated out of cash flows (i.e. a "collateral multiplier"). It is also endogenous and varies with $\bar{\varepsilon}$; as we shall see later, this is the reason why the volume of inside collateral is much more unstable than that of outside collateral, and collapses during crises. To understand the importance of $\theta$, assume that $\theta=1$. This means that banks can pledge the integrality of their cash flows as collateral. In this case, the collateral multiplier is above one (indeed, under Assumption 5, in equilibrium $\bar{\varepsilon}>\gamma$ ), banks create more inside collateral out of every new unit of funding. Ultimately, the moral hazard problem vanishes, and the economy reaches its first best allocation. We will assume that $\theta$ is low enough so as a moral hazard problem can arise (Assumption 4).

The parameter $f$ is not as critical as $\theta$, but nonetheless important. By inducing economies of scale, it allows us (i) to endogenize the number of subsidiaries, and therefore to relate the model to Fact \#2; and (ii) to relate - in a non-trivial way - the size of the banking sector, $s$, with the size of the collateral pyramid. As Figure 4 suggests, when $f=0$, an increase in savings always constricts the collateral pyramid, which is detrimental to financial efficiency. When $f>0$, in contrast, economies of scale kick in and a trade-off appears, as in this case an increase in savings also stimulates the creation of inside collateral. Economies of scale in the banking sector thus help relate the increase in savings (Figure 1) with that of secured lending (Figure 2), as observed in the run-up to the 2007-8 crisis.

The dependence of inside collateral on outside collateral stands in stark contrast with Krishnamurthy and Vissing-Jorgensen (2015), who view the two types of safe assets as substitutes. They too make a distinction between outside safe assets (treasuries) and inside safe assets (in their case, bank deposits). In their model, however, both types of safe assets are demanded by households for the non-pecuniary services those assets provide. When the supply and the yield of treasuries go down, households increase their demand for bank deposits. In contrast, in our case safe assets are engineered and supplied by banks as a way to alleviate financing constraints on the interbank market. When the supply of treasuries goes down, banks have less outside collateral to secure wholesale funding, and counter-party fears on the interbank market rise, which reduces the pledgeability of cash flows and the creation of inside collateral. In our case, 


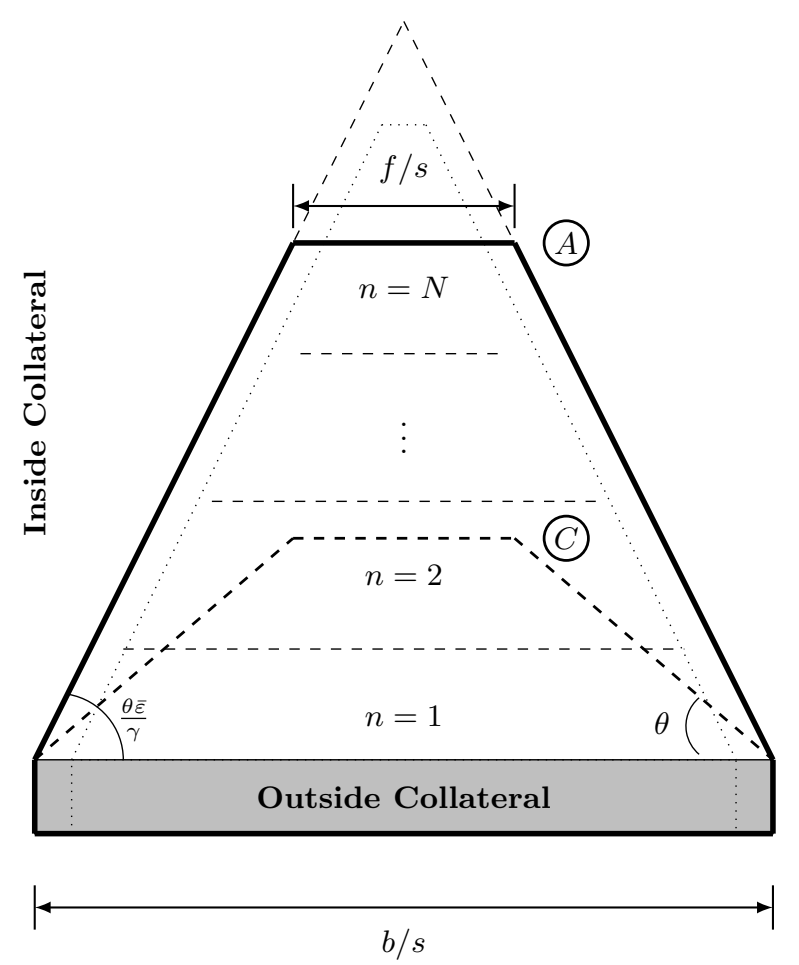

the two types of assets are therefore complements. Our model of the interbank market, which emphasizes the stages of the lending process, can be seen as a stylized representation of how the US shadow banking industry manufactured new financial products in the run-up to the 2008 financial crisis (see Coval, Jurek, and Stafford (2009); Pozard, Adrian, Ashcraft, and Boesky (2012)). To recap, the first step is to form a diversified pool of loans. The next step is to slice the pool and to issue a safe security backed by the information insensitive slice of the pool. This funding then gives rise to new projects and cash flows, which will be later used as collateral to raise new funding, and so on. In equilibrium lenders are indifferent as to which subsidiaries they lend to, and when ${ }^{13}$ So, in effect, the various rounds of lending are fully integrated, transactions take place simultaneously, and the interbank market clears instantaneously. Moreover, while our model is about single banks, banks can yet grow larger and more "complex" as new subsidiaries are created. In the discussion that follows we will think of $N$ not merely as being the number of rounds, but also as reflecting the number of subsidiaries per bank, a measure of complexity of the banking sector.

\subsubsection{Stage 1 Choices: Portfolio Choice}

Ex ante banks maximize the expected gross return on assets, denoted $\pi^{b}$, with respect to $b$ :

$$
\max _{b} \pi^{b} \equiv r s+b\left(r^{b}-r\right)+\left(s-b+\left(\phi^{b}+\phi^{c}\right) s\right) \int_{\bar{\varepsilon}}^{1}(\varepsilon a-r) d G(\varepsilon)
$$

\footnotetext{
${ }^{13}$ Implicitly, a lender goes to the interbank market only once. Given that the return on interbank loans is the same throughout the rounds, lenders are indeed indifferent.
} 
where $\phi^{b}$ is given by (4) and $\phi^{c}$ denotes the total amount of interbank loans secured by cash flows (i.e. $\phi^{c} \equiv \sum_{n=1}^{n=N} \phi^{c(n)}$. The return on assets is the sum of the returns on government bonds, interbank loans, and projects, weighted by the share of those assets in banks' assets. The second and third terms reflect the excess return on governments bonds and projects over interbank loans. This optimization problem already takes into account that, ex post, banks with $\varepsilon<\bar{\varepsilon}$ will be net lenders in the interbank market and banks with $\varepsilon \geq \bar{\varepsilon}$ will be net borrowers on the interbank market and invest into projects. Only the latter banks enjoy excess returns. From relations (4), (7), and (9) it is easy to see that the first order condition yields the arbitrage condition 12 in Lemma 1 below.

\subsubsection{Recap}

Putting together the stage 2 borrowing constraints and the stage 1 portfolio choice of the banks leads to a set of conditions that must hold in any interbank market equilibrium. These conditions are stated in Lemma 1 given $r$. The next section characterizes the determination of $r$.

Lemma 1. Given the interbank market rate $r$,

1. The bank with productivity $\bar{\varepsilon}$ is indifferent between borrowing and lending, with $\bar{\varepsilon}=r / a$;

2. An interior solution to bank optimization implies

$$
r^{b}=r
$$

3. The volume of loans backed by outside collateral is:

$$
\phi^{b}=\bar{\varepsilon} / \gamma-1+b / s
$$

4. The volume of loans backed by inside collateral, $\phi^{c}$, is:

$$
\phi^{c}=(\theta \bar{\varepsilon} / \gamma) \cdot(\bar{\varepsilon}-f /(a s)) /(\gamma-\bar{\varepsilon} \theta)
$$

5. The total outstanding amount of interbank loans, $\phi$, is:

$$
\phi \equiv \phi^{b}+\phi^{c}=(\bar{\varepsilon} / \gamma) \cdot(\gamma-\theta f /(a s)) /(\gamma-\theta \bar{\varepsilon})-1+b / s
$$

6. The number of subsidiaries per bank, $N$, is given by:

$$
N=(\ln (\bar{\varepsilon})-\ln (f /(a s))) /(\ln (\gamma)-\ln (\theta \bar{\varepsilon}))
$$


Proof. See Appendix 9.1 .

\section{Equilibrium Conditions}

This section describes the set of equilibria. A sunspot variable is included in the construction of an equilibrium as there may be multiple equilibria in the interbank market. The sunspot only serves as an indicator of expectations; no significant economic decisions are taken prior to its realization 14 Throughout the analysis we impose the following condition in order for inside collateral to be created and yet maintain a moral hazard problem:

Assumption 4. (Liquidation Cost, Seizable Cash Flow) (i) $\gamma>\theta$ and (ii) $\gamma a>f / s$.

The first part of Assumption 4 means that what borrowers get when they run away, $\gamma$, more than compensates their loss of the pledged assets, $\theta$, so that banks may gain from absconding. The second part of the assumption means that the fixed liquidation cost is not too large compared with the size of the economy, so that a inside collateral can emerge (i.e. $N>0$ ).

\subsection{Timing}

The timing of the interactions between households, banks, and the government is as follows: (1) the household deposits $s$; (2) the sunspot is revealed; (3) banks allocate deposits across government bonds $(b)$ and future investment $(s-b)$; (4) banks learn about the profitability of their projects, $\varepsilon$; and (5) banks decide to make either interbank loans, to invest into their project, or store goods.

\subsection{Market Clearing Conditions}

There are three markets: government bonds, interbank loans, and bank deposits. We solve for the equilibria, given savings $s$ and a stock of bonds $\mathbf{b}$. The interbank market equilibrium will determine $\bar{\varepsilon}$. Once this is known, the other components of the equilibria can be determined. The key to financial fragility comes from the multiple values of $\bar{\varepsilon}$ solving the interbank market clearing condition.

Government Bond Market. Since the government issues $\mathbf{b}$ bonds per bank, and each bank demands $b$, the market clears when:

$$
b=\mathbf{b} .
$$

Here $b$ reflects the holding of government bonds by the banks. By our timing, this decision is made after the realization of the sunspot and hence given the rate of return on interbank loans and government debt.

\footnotetext{
${ }^{14}$ One extension of the model would allow the strategic uncertainty to influence households' demand for bank deposits.
} 
Bank Deposit Market. Banks are identical ex ante, compete for depositors, and break even ex post. In equilibrium, the return on bank deposits is given by (using (11), (12) and (15)):

$$
r^{d} \equiv \frac{\pi^{b}}{s}=r\left(1+\frac{1-\frac{\theta}{\gamma a} \cdot \frac{f}{s}}{\gamma-\theta \bar{\varepsilon}} \int_{\bar{\varepsilon}}^{1}(\varepsilon-\bar{\varepsilon}) d G(\varepsilon)\right) .
$$

Under Assumption 4, the deposit rate is larger than the interbank loan rate and the return on government bonds. The spread reflects the shadow value of government bonds as collateral. Despite the low return on government bonds, banks are willing to hold such assets ex ante because they may pledge them as collateral later — once they learn their productivity $\varepsilon$ - to relax their financing constraints.

Interbank Market. Banks with $\varepsilon \geq \bar{\varepsilon}$ demand funds $\phi s$; so demand is $(1-G(\bar{\varepsilon})) \phi s$. Banks with $\varepsilon<\bar{\varepsilon}$ supply $s-\mathbf{b}$, provided that $\bar{\varepsilon}>\gamma$; in this case, those banks strictly prefer to lend than to store goods, and supply is $G(\bar{\varepsilon})(s-\mathbf{b})$. In the special case when $\bar{\varepsilon}=\gamma$, banks are indifferent between those two options, and so supply up to $G(\bar{\varepsilon})(s-\mathbf{b})$ on the interbank loan market. It follows that the market clearing condition is:

$$
(1-G(\bar{\varepsilon})) \phi\left\{\begin{array}{l}
=G(\bar{\varepsilon})(1-\mathbf{b} / s) \text { if } \bar{\varepsilon}>\gamma \\
\in[0, G(\bar{\varepsilon})(1-\mathbf{b} / s)] \text { if } \bar{\varepsilon}=\gamma
\end{array}\right.
$$

In $(19$ a), banks with $\varepsilon<\bar{\varepsilon}$ lend their entire wealth, $s-\mathbf{b}$, in the interbank market; they do not store goods. It is possible that the interbank market also clears with some of the low productivity banks using the storage technology. By arbitrage, this arises only when $\bar{\varepsilon}=\gamma$, as (19) suggests. Banks with $\varepsilon \geq \bar{\varepsilon}$ finance their projects with own funds $s-\mathbf{b}$ and by interbank loans, $\phi s$. Using (15) and (17), relation 19 can be re-written as:

$$
H(\bar{\varepsilon}) \equiv \frac{(1-G(\bar{\varepsilon})) \bar{\varepsilon}}{\frac{\gamma}{\theta}-\bar{\varepsilon}}\left\{\begin{array}{l}
=\frac{\theta\left(1-\frac{\mathbf{b}}{s}\right)}{1-\frac{\theta}{\gamma \cdot} \cdot \frac{f}{s}} \text { if } \bar{\varepsilon}>\gamma \\
\in\left[0, \frac{\theta\left(1-\frac{\mathbf{b}}{s}\right)}{1-\frac{\theta}{\gamma a} \cdot \frac{f}{s}}\right] \text { if } \bar{\varepsilon}=\gamma
\end{array}\right.
$$

Relation (20) is a convenient representation of the market clearing condition, as only its left side depends on $\bar{\varepsilon}$. As we will see later, the richness of the model will come from the non-monotonicity - i.e. the hump-shape- of $H(\bar{\varepsilon})$. As $\bar{\varepsilon}$ increases, the fraction of banks who borrow falls, and their average quality goes up. Since higher quality banks have less incentives to abscond, the amount they can borrow increases. That is, from $(15), \phi$ is increasing in $\bar{\varepsilon}$. The multiplicity will come from the interaction of these extensive and intensive margins. The term on the right side of (20a) decreases with aggregate productivity $(a)$, or as the fixed cost $(f)$ goes down. One can also show that, under Assumption $4, H(\bar{\varepsilon})$ goes up faster with the fraction of seizable cash flows $(\theta)$ than the term on the right hand side does, which means that the net demand of interbank loans increases with seizable cash flows. The return on storage, $\gamma$, has an 
opposite effect on net demand.

\subsection{Equilibria}

We discuss the types of equilibria that might arise and then give conditions for their co-existence. We will show that there are potentially multiple equilibria due to the asymmetric information and moral hazard of banks. For this discussion, we consider restrictions on $G(\cdot)$ and $\gamma$ so that those two frictions are meaningful:

Assumption 5. (Initial Resource Mis-allocation) (i) $G^{\prime \prime}(\bar{\varepsilon}) \geq 0 \forall \bar{\varepsilon} \in[0,1]$, and (ii) $\gamma<$ $\bar{\varepsilon}^{\max } \equiv \arg \max _{\bar{\varepsilon} \in[0,1]} H(\bar{\varepsilon})$.

Point (i) means that there is a sufficient mass of high $\varepsilon$-banks in the economy. Point (ii) means that the storage technology is (weakly) inefficient. Altogether, Assumption 5 means that deposits are initially mis-allocated across banks, and that there is scope for re-allocation through an interbank market. Under this assumption, $H(\bar{\varepsilon})$ is hump-shaped and reaches an interior maximum at $\bar{\varepsilon}=\bar{\varepsilon}^{\max } \in(\gamma, 1) \sqrt[15]{15}$ The hump shape of $H(\bar{\varepsilon})$ reflects the ambiguous effect of $\bar{\varepsilon}$ on loan demand, which decreases with $\bar{\varepsilon}$ on the extensive margin but increases with $\bar{\varepsilon}$ on the intensive margin. This latter unusual effect is due to the fact that borrowers' average quality goes up with $\bar{\varepsilon}$, as this works to relax banks' borrowing constraint. The negative intensive margin effect dominates when $1-G(\bar{\varepsilon})$ is large enough, that is when $\bar{\varepsilon}$ is low; in this case, the loan demand curve bends backward.

Definition 1. An equilibrium is a vector of returns $\left(r, r^{d}, r^{b}\right)$, a critical level of $\varepsilon$ denoted $\bar{\varepsilon}$, government bond holdings $b$, and borrowing limits $\phi^{b}, \phi^{c}$, such that

- Ex ante, banks choose b to maximize their expected return on deposits;

- Ex post, banks with

$-\varepsilon \geq \bar{\varepsilon}$ borrow in the interbank market up to the limit $\phi=\phi^{b}+\phi^{c}$;

$-\varepsilon<\bar{\varepsilon}$ either lend in the interbank market or store goods;

- $\phi^{b}$ and $\phi^{c}$ are determined so that banks with $\varepsilon \geq \bar{\varepsilon}$ invest rather than abscond;

- Beliefs about the distribution of types of banks borrowing in the interbank market are consistent with the equilibrium outcome;

- Markets for interbank loans, deposits and government bonds clear.

The flow of funds between banks is illustrated in Figure 5. As is clear, the determination of $\bar{\varepsilon}$ is fundamental to characterizing an equilibrium and determining the reallocation of funds within the banking sector through the interbank market.

\footnotetext{
${ }^{15}$ For a proof of this, see the Appendix.
} 
Figure 5: Interbank Reallocation and Financial Intermediation

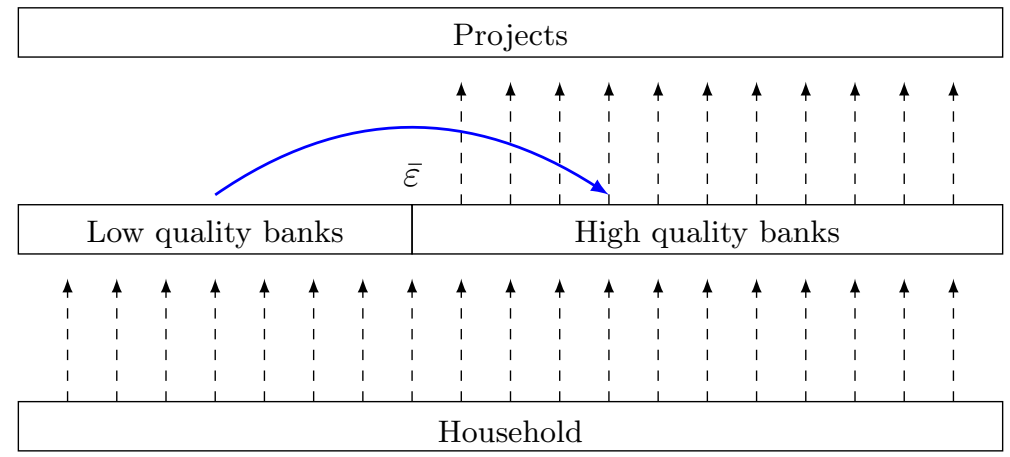

\subsubsection{Normal Times}

We first study outcomes which are solutions to 20,a. These solutions become the basis for a subset of the equilibria. The right side of $(20) \mathrm{a}$ is predetermined and constant. Under Assumption 5, the left side is hump shaped - the exact shape will depend on the assumed form for $G(\cdot)$ and the parameters of the model. As a consequence, a solution $\bar{\varepsilon}>\gamma$ to (20a) does not always exist. Equilibria in the interbank loan market are shown in Figure 6. Since banks always have the outside option to get a return $\gamma a$ by storing goods, only the values $\bar{\varepsilon} \geq \gamma$ are relevant. The figure illustrates one solution to $(20)$ at point $A$ (see also point $A$ in Figure 4). This equilibrium determines a value of $\bar{\varepsilon}>\gamma$ such that banks with $\varepsilon \geq \bar{\varepsilon}$ borrow on the interbank market, and will be referred to as "normal times". In this type of equilibrium, no bank uses the storage technology, and all deposits are invested into projects. From this value of $\bar{\varepsilon}$, we can construct an equilibrium as follows. Use (2) to determine the interbank rate: $r=\bar{\varepsilon} a$. From the no-arbitrage condition, (12), $r^{b}=r$. Relations (13) and (14) yield $\phi^{b}$ and $\phi^{c}$ given $\bar{\varepsilon}$. Finally, the equilibrium number of "rounds" in the interbank market that underlies $\phi^{c}$ is given by (16). Under Assumption 4, $\phi^{c}$ and $N$ are strictly positive.

Figure 6: Multiple Equilibria in the Interbank Market

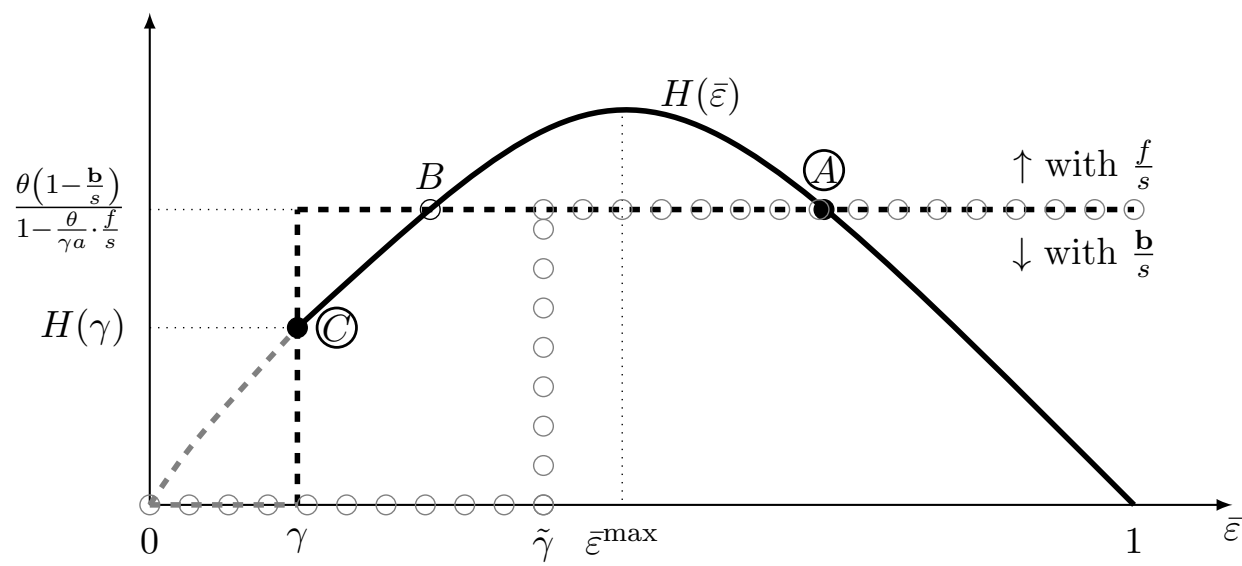

Since $H(\bar{\varepsilon})$ is hump-shaped, another interior solution (point $B$ ) can exist. Relative to $A$, 
the value of $\bar{\varepsilon}$ is lower, there are more banks borrowing but their borrowing constraint is tighter, loan quality is lower, and the intermediation process is less efficient. In the analysis that follows, we focus on the equilibrium at $A$ as it is locally stable and thus has "reasonable" comparative statics. But, as we shall see, there is another equilibrium outcome other than $B$ that is of interest.

\subsubsection{Collateral Trap}

Another equilibrium, which we term a "collateral trap", can arise as a solution to (20b) with $\bar{\varepsilon}=\gamma$. In this case, there is an excess supply of loans on the interbank market, and some banks store goods. Hence, aggregate productivity and output are low. In Figure 6, this equilibrium is represented by point $C$ (see also point $C$ in Figure 4). At this point, the banks with $\varepsilon \leq \gamma$ are indifferent between lending to other banks and storing goods, and they are the only banks that supply interbank loans. The supply of interbank loans is infinitely elastic, as illustrated by the vertical dashed line. In a collateral trap, banks engineer little inside collateral, and the borrowing constraint holds tight: productive banks, who cannot distinguish themselves from other banks, are unable to commit themselves to lending to projects, and therefore cannot raise more funding. Despite the low interbank rate, the demand for loans remains below supply, there is an excess supply of interbank funding, and the interbank market clears by having low productivity banks use the storage technology. This equilibrium exists if and only if (using $(20 \mathrm{~b}))$ :

$$
H(\gamma)<\frac{\theta\left(1-\frac{\mathbf{b}}{s}\right)}{1-\frac{\theta}{\gamma a} \cdot \frac{f}{s}} .
$$

Though some banks store goods, interbank borrowing is still possible, i.e. $\phi>0$, because banks can pledge as collateral both their government bonds as well as the cash flows of the projects that are operated ${ }^{16}$ However, the volume of collateral is reduced compared to normal times, and so is the level of interbank activity. On the one hand, banks are limited in the creation of safe assets, because counter-party fears on the interbank market reduce the degree of pledgeability of the cash flows. On the other hand, counter-party fears are high because banks have little safe assets to pledge as collateral. Hence the collateral trap. In Figure 6 . the collateral trap equilibrium in $C$ co-exists with the normal times equilibrium in $A$. In this sense, the interbank market is susceptible to swings in confidence. It is natural to associate outcomes like $A$ with optimism about the quality of borrowing banks, with high returns on interbank loans and relaxed borrowing restrictions. It is also natural to think of crises, like $C$, as the outcome of pessimism. $A$ and $C$ are self-fulfilling equilibria. Assume for example that banks are pessimistic: they believe that unproductive banks demand interbank funding. Since

\footnotetext{
${ }^{16}$ If $\mathbf{b}=0$ (no outside collateral) and $\theta=0$ (no inside collateral) then in a collateral trap $\phi=0$ and there is no demand for interbank loans.
} 
Figure 7: Unique Equilibrium Configurations

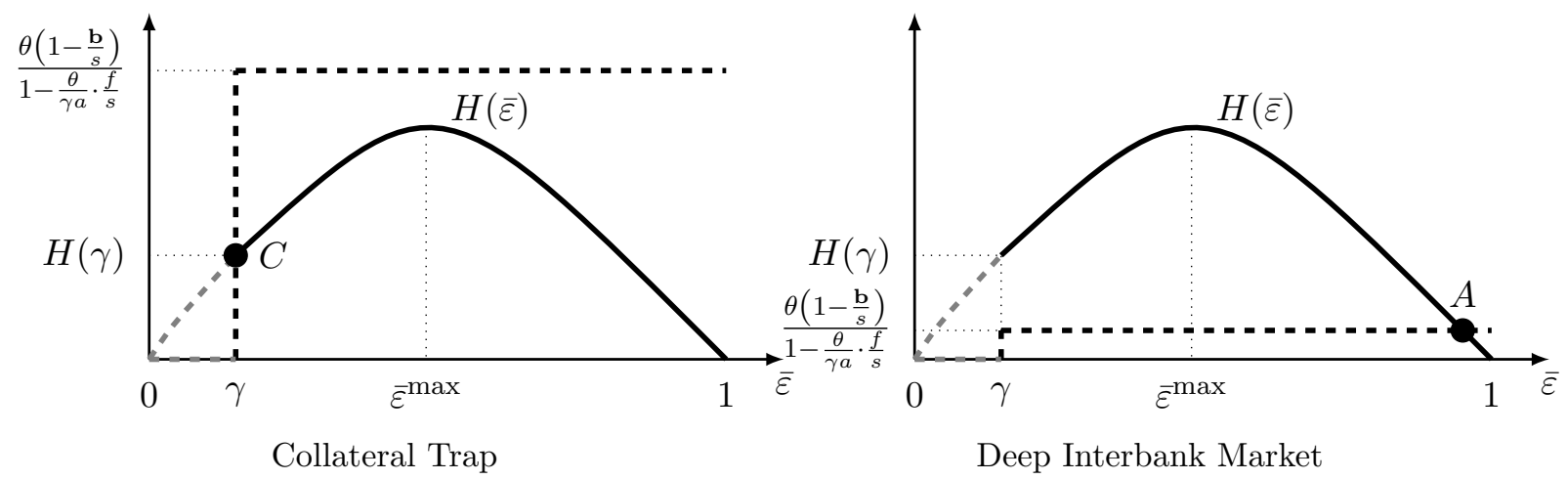

unproductive banks are prone to absconding, lenders require borrowers to put more "skin in the game", and reduce $\phi$. As every borrower demands less funding, the equilibrium interbank loan rate goes down, and the net present value of the unproductive banks' projects increases. Hence, unproductive banks do indeed demand interbank funding.

\subsubsection{Conditions for a Collateral Trap}

Not all economies possess multiple equilibria. Other possible outcomes are illustrated in Figure 7. which shows cases of unique equilibria. In panel (a), there are no solutions to (20) there is a collateral trap equilibrium. In panel (b), by contrast, there is a solution to (20a) but not to (20 b); in this case the normal times equilibrium is the only possible outcome. To describe the conditions of existence of a collateral trap and normal times equilibria, it is useful to define two critical levels of government debt, $\bar{b}$ and $\underline{b}$, as:

$$
\bar{b}=\frac{f}{\gamma a} H(\gamma)+\left(1-\frac{H(\gamma)}{\theta}\right) s
$$

and

$$
\underline{b}=\frac{f}{\gamma a} H\left(\bar{\varepsilon}^{\max }\right)+\left(1-\frac{H\left(\bar{\varepsilon}^{\max }\right)}{\theta}\right) s
$$

with $\underline{b}<\bar{b}$. There are three regions for the level of public debt. In the upper dominance region, with $\mathbf{b}>\bar{b}$, banks can use so much public debt as collateral that crises are ruled out, irrespective of banks' beliefs about borrowers' quality in the interbank market. Then there is a lower dominance region, with $\mathbf{b}<\underline{b}$, where instead there is a shortfall of pledgable assets in the economy. The government did not issue enough debt to avoid the collateral trap. Finally, there is an intermediate region, where beliefs matter and sunspot equilibria arise; in this case, crises are self-fulfilling. Proposition 1 formalizes this characterization.

\section{Proposition 1. (Equilibrium)}

- When $\boldsymbol{b}<\underline{b}$, there is a unique collateral trap equilibrium, with $\bar{\varepsilon}=\gamma$ as solution to (20b); 
- When $\boldsymbol{b}>\bar{b}$, there is a unique normal times equilibrium, with $\bar{\varepsilon}>\bar{\varepsilon}^{\text {max }}$ as solution to (20a);

- When $\boldsymbol{b} \in[\underline{b}, \bar{b}]$, there are sunspot equilibria, with either $\bar{\varepsilon}>\bar{\varepsilon}^{\text {max }}$ or $\bar{\varepsilon}=\gamma$.

Proof. The results follow directly from the definition of $\bar{b}$ and $\underline{b}$ in $(22)$ and $(23)$.

\section{Equilibrium Analysis}

In this section we discuss the main properties of the equilibria, compare collateral traps and normal times, and analyse the effects of savings on the operation of the interbank market.

\subsection{Aggregate Output and Consumption}

For the discussion, it is useful to derive aggregate output, $y$, as the sum of the outputs of banks' projects and storage:

$$
y=\underbrace{\int_{\bar{\varepsilon}}^{1} \varepsilon a((1+\phi) s-\mathbf{b}) \mathrm{d} G(\varepsilon)}_{\text {projects }}+\gamma a \underbrace{((s-\mathbf{b}) G(\bar{\varepsilon})-(1-G(\bar{\varepsilon})) \phi s)}_{\text {storage }},
$$

which using relation 15 and Proposition 1 yields:

$$
y=\left\{\begin{array}{l}
\frac{s-\mathbf{b}}{1-G(\bar{\varepsilon})} \int_{\bar{\varepsilon}}^{1} \varepsilon a \mathrm{~d} G(\varepsilon) \text { in normal times } \\
\frac{1-\frac{\theta}{\gamma a} \cdot \frac{f}{s}}{1-\theta} s \int_{\gamma}^{1}(\varepsilon-\gamma) a \mathrm{~d} G(\varepsilon)+\gamma a(s-\mathbf{b}) \text { otherwise. }
\end{array}\right.
$$

Aggregate output is determined both by the size of the economy $s$ and by the degree of efficiency, $\bar{\varepsilon}$, with which the banking sector allocates resources across projects. Since the household consumes aggregate output (i.e. $c=y$ ), consumption too is determined by the level of $\bar{\varepsilon}$. Both output, consumption, and welfare increase with $\bar{\varepsilon}$.

\subsection{Comparing Outcomes: Collateral Traps versus Normal Times}

The key feature of collateral traps is the reduction in $\bar{\varepsilon}$; this has important implications. First, at a lower $\bar{\varepsilon}$, a larger fraction of banks borrow in the interbank market. This increase on the extensive margin means that lower productivity banks that would lend to higher productivity banks during normal times actually borrow in a collateral trap. The fact that low productivity banks demand funding raises counter-party fears, and therefore reduces the degree of pledgeability of cash flows. Hence, in a collateral trap, the collateral multiplier is low, as illustrated by the smaller collateral pyramid $C$ in Figure 4. Countering this change on the extensive margin is also a reduction in borrowing limits. With lower quality banks borrowing, these limits fall to avoid moral hazard. In addition to the reduction in size of the interbank loans, there is a composition effect. Specifically, the volume of inside collateral collapses and the share of outside 
collateral in total collateral goes up. Essentially, the limit on the borrowing backed by outside collateral $\left(\phi^{b}\right)$ is less sensitive than that on the borrowing backed by the cash flow from projects $\left(\phi^{c}\right)$, because the latter is also driven by variations in the collateral multiplier. In a collateral trap there is less activity in the interbank market, and some banks store goods, which reduces aggregate productivity. This fall in productivity has not only an overall negative real effect on the levels of output, consumption, and welfare, but also a positive effect on the cross-sectional dispersion of banks' returns. The output and productivity implications are consistent with the evidence in Foster, Grim, and Haltiwanger (2013). To the extent the Great Recession contained more of a financial collapse than other recessions, the implications of our model, which attributes recessions to the collapse of the interbank market, are relevant.

Proposition 2. (Features of a Collateral Trap) Relative to normal times and all other things being equal, in a collateral trap:

1. the cut-off bank productivity, $\bar{\varepsilon}$, is lower;

2. the interbank loan rate, $r$, is lower;

3. the spread between the deposit rate and the interbank loan rate (and therefore the shadow value of government bonds as collateral) is higher;

4. the spread between the government bond yields and the interbank loan rate remains null;

5. the volume of interbank transactions secured by outside collateral, $\phi^{b}$, is lower;

6. the volume of interbank transactions secured by inside collateral, $\phi^{c}$, is lower;

7. the ratio $\frac{\phi^{b}}{\phi^{c}}$ is higher;

8. there are fewer bank subsidiaries ( $N$ is lower);

9. banks store goods, and not all deposits (net of government bonds) are used to finance productive projects;

10. output, consumption and welfare fall;

11. the cross-sectional dispersion of bank productivity (the $\varepsilon s)$ is higher.

Proof. See Appendix 9.3 .

\subsection{Effects of Savings on Financial Stability, Efficiency, and Complexity}

The rapid increase in bank deposits and the large demand for safe assets addressed to the US banking sector by the rest of the world (see Figure 1) has been put forward as one of the key structural factors behind the 2007-8 financial crisis (see, e.g., Caballero and Krishnamurthy 
(2009)). The aim of this section is to shed light on the relationship between savings and financial stability, efficiency, and complexity. In the context of our model, we interpret the size of the region of multiplicity as indicative of financial instability: the larger $\bar{b}-\underline{b}$, the higher the degree of financial instability. There is a distinction between financial stability and financial efficiency. The financial sector can be efficient and yet unstable, as in Point A on Figure 6; or it can be stable and yet inefficient, as in Point $\mathrm{C}$ on Figure 7 or it can be both stable and efficient, as in Point A in Figure 7.

Proposition 3. (Savings and Stability) An increase in savings $s$ widens the range of government debt levels, $\bar{b}-\underline{b}$, for which there are multiple equilibria, and thus is conducive to interbank market instability. Moreover, following the increase in s, the level of government debt required to rule out crises (b) goes up if $\theta<G(\gamma)$.

Proof. From Appendix 9.2, $\bar{\varepsilon}^{\max }$ is independent of $s$. Using $(22)$ and $(23)$, it is easy to see that $(\bar{b}-\underline{b}) / s$ is proportional to $(1-\theta f /(\gamma a s))$, which increases monotonically with $s$; hence $\bar{b}-\underline{b}$ increases with $s$. From relation 22 it is clear that $\bar{b}$ increases with $s$ if and only if $\theta>H(\gamma)$, which is equivalent to (using the definition of $H(\bar{\varepsilon})$ in $(20)) \theta<G(\gamma)$.

Proposition 3 means that the rise in bank deposits not only is detrimental to financial stability but also can trigger a crisis if following the rise $\bar{b}$ goes up above $\mathbf{b}$. This may happen when $\theta$ is small $(\theta<G(\gamma))$ and the banking sector creates too little inside collateral out of the additional savings to make it up for the reduction in the collateral base, $\mathbf{b} / s$. Besides influencing the range of multiplicity, the level of savings also has an effect on the degree of efficiency and complexity of the banking sector in normal times.

Proposition 4. (Savings and Efficiency) Following an increase in savings, financial efficiency $(\bar{\varepsilon})$ deteriorates in normal times if $\boldsymbol{b} / f>\theta /(\gamma a)$.

Proof. From Figure 6 it is easy to see that $\bar{\varepsilon}$ goes down with $s$ if the term on the right hand side of $(20)$ increases with $s$, that is, if $\mathbf{b} / f>\theta /(\gamma a)$.

Proposition 5. (Savings and Complexity) There exists $\epsilon>0$ such that, if $\boldsymbol{b} / f<\theta /(\gamma a)+\epsilon$, then an increase in savings $s$ raises the complexity of the banking sector, $N$, in normal times.

Proof. From relation (16), $N$ is a continuous, increasing function of both $s$ and $\bar{\varepsilon}$. The direct effect of $s$ is independent of $\mathbf{b}$. The indirect effect of $s$ goes through $\bar{\varepsilon}$ and - from Proposition 4 is negative if $\mathbf{b} / f>\theta /(\gamma a)$, and positive otherwise. It follows that there exists $\epsilon>0$ such that those two effects exactly offset each others when $\mathbf{b} / f=\theta /(\gamma a)+\epsilon$. Hence, the overall effect of $s$ on $N$ is positive if and only if $\mathbf{b} / f<\theta /(\gamma a)+\epsilon$.

The results in Propositions 4 and 5 reflect the ambiguous effects of an increase in savings on collateral availability. To see this, compare in Figure 4 the collateral pyramid before the 
increase in savings, delineated by the thick black line, with that after, delineated by the dotted line. When $s$ goes up, the volume of outside collateral relative to savings $(b / s)$ diminishes, and the base of the pyramid shrinks. However, as projects grow larger, economies of scale make the fixed liquidation cost and the financial engineering of new assets affordable (i.e. $\mathrm{f} / \mathrm{s}$ decreases); the height of the pyramid goes up. When $\mathbf{b} / f=\theta /(\gamma a)$, then the two effects exactly offset each other. The economy creates endogenously exactly the same amount of inside collateral as the amount of outside collateral it lost. In this case, financial efficiency does not change, but the banking sector is more complex and less stable.

\section{Back to the Facts}

We use our model to understand the link between the observed increase in savings and shortage of outside collateral (Facts \#1) and the evolution in interbank market flows and interest rates before and during the 2007-8 crisis (Facts \#2 and \#3). The model is structured around "normal" and "crisis" times. With this in mind, the pre-crisis period, roughly from 2003 to mid-2007, is viewed as "normal" times. The crisis begins at that point.

\subsection{Pre-Crisis}

Figure 1 shows that the increase in the level of household deposits and holding of US treasuries by the rest of the world accelerated from 1995 to the onset of the crisis and that, over the same period, the volume of US treasuries held by the US financial sector fell like never before. As a consequence, in 2008 the treasuries-to-deposit ratio of the US financial sector was less than half of what it was in 2003. At the same time the number of SPVs increased and the volume of collateralised lending rose (see Figure 2). One interpretation of those events is that the US banking sector became more complex and engineered collateralised debt as substitutes to treasuries to quench the rest of the world's thirst for US safe assets (this is consistent with Caballero (2009)). From the perspective of our model, the increase in bank deposits is seen as an increase in $s$ and the fall in treasuries as a decrease in $\mathbf{b}$ (see Fact \#1 and Figure 1). The creation of SPVs and the rise in ABCP markets is seen as the number of subsidiaries $N$ going up (Fact \#2). Our interpretation of those events is that, by reducing US banks' collateral base $b / s$, the crowding of US banks out of treasuries by the rest of the world made the US financial system more fragile. The concomitant increase in deposits enabled banks to generate more cash flows and to create more inside collateral, as through economies of scale the number of SPVs increased. These dynamics resulted in a change in the composition of banks' collateral, with the relative increase in inside collateral. From a financial stability perspective, this change is important, as the wholesale funds secured by cash flows are less stable than those secured by treasuries; they are subject to changes in beliefs. Based on our model, we argue that the reduction in the volume of US treasuries held US banks drove the economy from the upper dominance region (with $\mathbf{b}>\bar{b}$ ) into the multiple equilibrium or the collateral trap region (with 
$\mathbf{b} \leq \bar{b})$; hence the crisis.

\subsection{Crisis: Falling into the Collateral Trap}

We interpret events post-2008 as a fall in confidence of lenders in the interbank market, made possible by the change in collateral composition. In our model, a crisis is defined by a dramatic fall in cut-off productivity determining the borrowers and lenders in the interbank market $(\bar{\varepsilon})$. The implications of this switch from optimistic to pessimism are summarized in Proposition 2 . During the crisis, the repo rate $(r)$ and the ratio between the repo and the corporate loan rates $(\bar{\varepsilon})$ fell, as as seen in Figure 3, and so did the repo, ABCP and ABS-CDO activity (relative to deposits), as seen in Figure 2. The latter figure also shows that repo activity fell relatively little to stabilize at its 2003 level, whereas the ABS-CDO activity fell by over $80 \%$ from its 2007 peak. The ABCP volume fell more than repo but less than the ABC-CDO volumes. These relative flows (Fact \#2) are in accord with the model's predictions, particularly items 8-9 in Proposition 2. We interpret the ABCP flow as indicative of $\phi^{c(1)}$ and the more dramatic reduction in ABS-CDO as reduction in the number of SPVs, $N$.

\section{Policy Responses}

Our focus is on analyzing policies intended to increase household consumption. To discipline our discussion, we assume that, absent any policy interventions, there initially exist multiple equilibria (i.e. $\mathbf{b} \in[\underline{b}, \bar{b}]$ ). In this context, one question that we ask is, whether policy interventions can guide the economy out of multiplicity toward the normal times equilibrium. Formally, this amounts to discussing which policy lowers the upper dominance region threshold, $\bar{b}$. As expression (22) shows, this threshold depends on two different types of parameters, namely: the parameters governing the collateral creation process, $\theta$ and $f$; and those governing the banks' returns, $\gamma$ and $a$. We discuss the policies related to those parameters in turn.

\subsection{Narrow Banking}

The first type of intervention that we consider is a restriction on the assets that can be pledged as collateral in interbank trades. We refer to such a restriction as "narrow banking". In the context of our model, narrow banking takes the form of an interdiction to pledge as collateral the future cash flows from projects. This corresponds to a reduction in the recovery rate $\theta$ down to zero. Gorton and Metrick (2010) recently proposed a similar intervention, with the creation of regulated "narrow funding banks", whose regulator would decide which classes of assets are eligible as collateral ${ }^{17}$ In our case, only the interbank trades secured by government debt are feasible, interbank loans are backed by outside collateral only $\left(\phi^{n}=0\right.$ and $\left.\phi=\phi^{b}\right)$, and financial complexity is eliminated $(N=0)$.

The following proposition compares the equilibrium without inside collateral to the outcome

\footnotetext{
${ }^{17}$ For a discussion of similar narrow banking proposals, see e.g. Chow and Surti (2011).
} 
with inside collateral.

Proposition 6. (Narrow Banking) The introduction of narrow banking does not rule out the collateral trap, may eliminate the normal times equilibrium ( $\bar{b}$ goes up), and impairs the functioning of the interbank market in normal times ( $\bar{\varepsilon}$ goes down), if such an equilibrium still exists. Whatever the initial level of $\boldsymbol{b} \in[\underline{b}, \bar{b}]$, narrow banking reduces consumption both in normal times and in the collateral trap.

Proof. It is easy to see from $(20)$ that both $H(\bar{\varepsilon})$ and $\bar{\varepsilon}^{\text {max }}$ increase monotonically with $\theta$, and therefore that $\bar{b}$ and $\underline{b}$ decrease with $\theta$ (from $(22)$ and $(23)$ ). It follows that, under narrow banking (i.e., for $\theta=0$ ) the normal times equilibrium may be eliminated ( $\underline{b}$ goes up), the collateral trap is not eliminated ( $\bar{b}$ does not go down), and the banking sector is less efficient $(\bar{\varepsilon}$ is lower) in the normal time equilibrium, if such an equilibrium still exists. Since the banking sector is less efficient in normal times, output is lower, and so is consumption in normal times (from (24)). Finally, since no inside collateral is created, there is less reallocation in a collateral trap, and both output and consumption go down.

The implications of this intervention are clear. First, the normal times equilibrium has a lower level of $\bar{\varepsilon}$ than in the comparable equilibrium with valued inside collateral. This reduction in $\bar{\varepsilon}$ means that $\phi$ is lower in the economy without inside collateral. Accordingly, the reallocation through the interbank market is reduced.

Second, the collateral trap remains and is associated with even less funding of projects. For this economy, collateral restrictions not only do not eliminate the moral hazard and asymmetric information frictions but also reduce the ability of the banking system to respond to these sources of inefficiency. This makes clear that a collateral trap does not arise because of the presence of inside collateral: multiple equilibria can exist even if all loans are backed by outside collateral.

Also, notice that it is possible that collateral restrictions eliminate the multiplicity of equilibria. But this occurs by supporting a unique equilibrium with low interbank flows. This is exactly the same outcome as in the collateral trap, so that the intervention does not improve welfare.

\subsection{Bank Subsidy}

The second policy intervention is a government subsidy that raises the return on projects. Since the subsidy is conditional on the bank operating its projects, it resembles a conditional bank capital injection by a government, akin to the US Treasury's 2009 "Capital Assistance Program". Indeed, under this program, banks received capital from the Treasury conditional on them lending to the real economy 18 The subsidy is announced at the beginning of the period,

\footnotetext{
${ }^{18}$ More precisely, as part of the application process, US banks were required to submit a plan for how they intended to use the capital injected to preserve and strengthen their lending capacity. The access to the program
} 
and is financed by a lump sum tax on the household at the end of the period.

In the context of our model we assume that banks are given ex post a subsidy that raises the unit return of their projects from $a$ to $\tilde{a}$, with $a>\tilde{a}$. The following proposition compares the equilibrium without the subsidy to the outcome with the subsidy.

Proposition 7. (Bank Subsidy) A subsidy on projects may eliminate the collateral trap equilibrium, and always improves the functioning of the interbank market, be it in normal times or in the collateral trap. The effect of such a subsidy on consumption is positive in both cases.

Proof. Following the rise in $a$, the term on the right hand side of 200 decreases. Hence, the banking sector is more efficient in normal times ( $\bar{\varepsilon}$ goes up). From 22 it is easy to see that $\underline{b}$ goes down, which means that the collateral trap equilibrium may be avoided. Since in normal times $\bar{\varepsilon}$ is higher, so are output and consumption (see (24)). Finally, since the subsidy stimulates the creation of inside collateral, there is also more reallocation in a collateral trap, less deadweight losses, and hence higher output and consumption.

By giving banks more incentives to operate their projects, the subsidy mitigates the moral hazard problem on the interbank market. For a given volume of collateral, the demand for interbank loans goes up, and so does the equilibrium interbank rate. As a consequence, $\bar{\varepsilon}$ goes up: some unproductive banks that were borrowing on the interbank market now lend, and funds are allocated to the best projects. As the quality of borrowers goes up and their heterogeneity diminishes, the asymmetric information problem recedes, and a larger fraction of cash flows become pledgeable, which further relaxes the borrowers' collateral constraint. Hence the positive effect of a subsidy on the economy.

\subsection{Deposit Facility}

The next intervention that we consider is the opening of a deposit facility by a central bank, through which the latter offers banks interest-bearing deposits. One recent example of such intervention is the "Term Deposit Facility", which the US Federal Reserve Bank established in 2008.

To analyse this policy we assume that banks now have the possibility to deposit their excess cash with a central bank at a rate of return $\tilde{\gamma} a$, with $\tilde{\gamma}>\gamma$. Hence, banks have two outside options: storage and central bank deposits. Moreover, we assume that banks cannot abscond with funds deposited at the central bank, and that the central bank stores those funds. Hence, central bank deposits are not being used productively, and the government raises lump sum taxes from the household at the end of the period to make it up for the central bank's losses (i.e. for $\tilde{\gamma}-\gamma)$.

was also conditional on restrictions on dividend payments, executive compensation requirements, etc. 
The following proposition compares the equilibrium without the deposit facility to the outcome with the deposit facility.

Proposition 8. (Deposit Facility) The existence of a deposit facility eliminates the collateral trap equilibrium if and only if the offered deposit rate, $\tilde{\gamma} a$, is above a certain threshold. In the normal times equilibrium, the deposit facility is not used, and consumption is the same as in a normal times equilibrium without deposit facility. In the collateral trap (if this equilibrium still exists), the deposit facility is used and consumption is higher than without deposit facility.

Proof. Let $\bar{\varepsilon}^{B}$ be the smallest solution to equation (20); this solution corresponds to point $B$ in Figure 6, with $\bar{\varepsilon}^{B}>\gamma$. Then, by construction, the collateral trap is still a possible outcome if and only if aggregate demand intersects aggregate supply for $\bar{\varepsilon}=\tilde{\gamma}$, that is, if and only if $\bar{\varepsilon}^{B} \leq \tilde{\gamma}$. It follows that the threshold for $\tilde{\gamma}$, above the collateral trap is avoided, is $\bar{\varepsilon}^{B}$. In the collateral trap (if this equilibrium still exists), the banks that borrow funds on the interbank market are on average more productive, and output and consumption are therefore higher, than without the deposit facility.

One important result in Proposition 8 is that a central bank can eliminate coordination failures on the interbank market by setting its deposit facility rate high enough. Indeed, as the central bank raises $\tilde{\gamma}$, it also reduces banks' supply of funds on the interbank market, and the equilibrium interbank increases. This, in turn, gives unproductive banks more incentives to lend, which by resorbing the asymmetry of information about borrowers' quality helps avoid the collateral trap. The use of central bank deposit as coordination device is illustrated in Figure 6. The gray circles represent the supply curve after the central bank opens the deposit facility. For a rate of return below $\tilde{\gamma} a$, there is no supply, and point $C$ is ruled out as an equilibrium. Banks then coordinate on the normal time equilibrium in $A$, where the interbank rate is above $\tilde{\gamma} a$; in this equilibrium, banks do not use the central bank's deposit facility.

\subsection{Collateral Swap}

In March 2008, the Federal Reserve set up the TSLF program, which gave banks (in effect, primary dealers) the possibility to bid a fee to borrow Treasury securities from the Fed for one month, while agreeing to provide other (less liquid) securities as collateral in exchange. Banks could then use the borrowed Treasury securities as collateral to obtain cash in the private markets. Fleming, Hrung, and Keane (2010) show that such a measure precipitated a significant narrowing of repurchase agreement (repo) spreads between Treasury collateral and less liquid collateral and that, overall, the provision of Treasury collateral through the TSLF mitigated a more general shortage of liquid collateral.

The last intervention that we consider is similar to the TSLF. We assume that the government issues new government debt, and swaps every unit of the new debt against $1 / \tilde{\theta}$ units of 
cash flow from projects at the beginning of the period, with $\tilde{\theta} \in(0,1)$. At the end of the period, all swaps are reversed, and banks get their corporate claims back 19 Following those swaps, banks then have the possibility to pledge the new government bonds as collateral instead of cash flows.

Proposition 9. (Collateral Swap) A collateral swap may rule out the collateral trap only if $\tilde{\theta}>\theta$. In any case, the policy always improves the functioning of the interbank market and the channelling of savings toward the best projects. Hence, the effect on aggregate output and consumption is always positive.

Proof. The results follow from the fact that the collateral swap has the same effect as an increase in $\theta$ up to $\tilde{\theta}$.

The collateral swap policy enhances the pledgeability of banks' cash flows, so that banks have more skin in the game, and lose more if they abscond. The effects of this policy are therefore similar to those of a bank subsidy (Section 7.2).

\section{Conclusion}

In this paper we explore how banks' holdings of outside collateral (like treasuries) affect banks' production of inside collateral, and how this collateral creation process affects the efficiency and stability of wholesale financial markets. We highlight sudden swings in both collateral value and collateral creation as a source of fragility in interbank markets leading to a collateral trap.

Due to the presence of moral hazard and adverse selection, loans between heterogeneous banks have two main features. First, these loans are collateralized, either by treasuries (outside collateral) and/or cash flows (inside collateral). Second, limits emerge endogenously on the amount banks can borrow in this market. Confidence is central to the functioning of the interbank market. When lenders are optimistic about the quality (productivity) of borrowing banks, quantity restrictions are relatively lax and interbank loan rates are high. In equilibrium, only high productivity banks borrow in the market and the reallocation of deposits across banks is relatively efficient.

But, for the same parameters, the economy may be stuck in a collateral trap. In this case, lenders are pessimistic about bank quality. The volume of inside collateral is low, borrowing restrictions are tight, and lending rates are low. Relatively low productivity banks borrow so that the interbank market is much less efficient in the reallocation of deposits. The reduction in interbank flows is more pronounced in loans backed by inside collateral than in loans backed by outside collateral.

\footnotetext{
${ }^{19}$ In effect, those swaps can be seen as the government lending government debt securities to the banks against the corporate cash flows as collateral. The securities lending transactions unravel at the end of the period, and banks collect cash flows; in this way, we make sure that even the banks with a high $\varepsilon$ are willing to enter the swap, and that the productivity of bank $\varepsilon$ cannot be revealed based on whether or not the bank enters the swap.
} 
The disruption of financial reallocation in a collateral trap has real effects as well. The most profitable banks are unable to attract the flow of funds they would receive in normal times. The aggregate economy is less productive: output, consumption and welfare are lower.

Though the model is purposefully simple, structured to capture the interactions of inside and outside collateral, it is capable of matching some key features of the recent financial crisis. This includes the reduction in the interbank loan rate, the fall in the flow of funds financed by inside collateral relative to outside collateral and the consequent fall in output.

Finally, we use the model to discuss the effects of four policies on financial efficiency and stability. A key finding is that asset portfolio restrictions are costly in terms of welfare; indeed, such restrictions may eliminate the fragility of these markets but they do so by supporting a unique equilibrium with low interbank flows. We also find that bank subsidies, a central bank deposit facility, and collateral swaps contribute to the stability of the financial sector.

\section{References}

Acharya, V., P. Schnabl, and G. Suarez (2013): "Securitization without risk transfer," Journal of Financial Economics, 107(3), 515-536.

Acharya, V. V., And P. Schnabl (2010): "Do Global Banks Spread Global Imbalances\&quest; Asset-Backed Commercial Paper during the Financial Crisis of 2007-09," IMF Economic Review, 58(1), 37-73.

BCBS (2009): "Report on Special Purpose Entities," BIS, The Joint Forum.

Benmelech, E., and N. Bergman (2012): "Credit Traps," American Economic Review, 102(6), 3004-32.

Caballero, R. (2009): "The "Other" Imbalance and the Financial Crisis," MIT, Working Paper 09-32.

Caballero, R., and E. Fahri (2015): "The safety trap," Mit, mimeo.

Caballero, R. J., and A. Krishnamurthy (2009): "Global Imbalances and Financial Fragility," American Economic Review, 99(2), 584-88.

Chow, J., And J. Surti (2011): "Making Banks Safer: Can Volcker and Vickers Do It?," IMF Working Paper \#WP/11/236.

Copeland, A., A. Martin, and M. Walker (2011): "Repo run: evidence from the tri-party repo market," Discussion paper, Staff Report, Federal Reserve Bank of New York.

Coval, J., J. Jurek, And E. Stafford (2009): "The Economics of Structured Finance," Journal of Economic Perspectives, pp. 3-25. 
Covitz, D. M., N. Liang, and G. A. Suarez (2009): "The evolution of a financial crisis: Panic in the asset-backed commercial paper market," Discussion paper, Division of Research \& Statistics and Monetary Affairs, Federal Reserve Board.

Diamond, D. W., And P. H. Dybvig (1983): "Bank runs, deposit insurance, and liquidity," Journal of Political Economy, pp. 401-419.

Fleming, M. J., W. B. Hrung, and F. M. Keane (2010): "Repo market effects of the term securities lending facility," The American Economic Review, pp. 591-596.

Foster, L., C. Grim, and J. Haltiwanger (2013): "Reallocation in the Great Recession: Cleansing or Not?," US Census Bureau Center for Economic Studies Paper No. CES-WP$13-42$.

Gorton, G. (1988): "Banking Panics and Business Cycles," Oxford Economic Papers, 40, $751-781$.

Gorton, G., And A. Metrick (2010): "Regulating the Shadow banking System," Brookings Papers on Economic Activity, pp. 26-312.

(2012): "Securitized banking and the run on repo," Journal of Financial Economics, 104(3), 425-451.

Gorton, G., And G. Ordonez (2014): "Collateral Crises," American Economic Review.

Gorton, G., and N. Souleles (2005): "Special Purpose Vehicles and Securitization," NBER discussion paper \# 11190.

Holmstrom, B., And J. Tirole (1998): "Private and public supply of liquidity," Journal of Political Economy, 112, 1-40.

Kiyotaki, N., And J. Moore (1997): "Credit cycles," Journal of Political Economy, 105, $211-248$.

Krishnamurthy, A., S. Nagel, and D. Orlov (2014): "Sizing up repo," The Journal of Finance.

Krishnamurthy, A., And A. Vissing-Jorgensen (2012): "The aggregate demand for treasury debt," The Journal of Political economy.

(2015): "The impact of treasury supply on financial sector lending and stability," Stanford University, mimeo.

Pozard, Z., T. Adrian, A. Ashcraft, and H. Boesky (2012): "Shadow Banking," Federal Reserve Bank of New York Staff Report \#458. 
Tirole, J. (2006): "The Theory of Corporate Finance," Princeton University Press.

\section{Appendix}

\subsection{Proof of Lemma}

A bank of productivity $\varepsilon$ who borrows $B$ on the interbank market obtains $\varepsilon a(s-b+B)-r B$ from borrowing and financing projects. That same bank can earn $r(s-b)$ from lending on the interbank market. Therefore, a bank with $\varepsilon=\bar{\varepsilon} \equiv r / a$ is just indifferent between borrowing and lending on the interbank market, regardless of the amount it can borrow, $B$ (item 1). Iterating (9) links $\phi^{c}(n)$ to $\left(1-\frac{b}{s}+\phi^{b}\right): \phi^{c(n)}=(\theta \bar{\varepsilon} / \gamma)^{n}\left(1-b / s+\phi^{b}\right)$. Using this in 10 and solving for the $n=N$ such that 10 is met with equality yields:

$$
\left(\frac{\theta \bar{\varepsilon}}{\gamma}\right)^{N}\left(1-\frac{b}{s}+\phi^{b}\right)=\frac{f}{\gamma a s}
$$

Putting the rounds together, one gets the total amount of interbank loans secured by inside collateral:

$$
\phi^{c}=\sum_{n=1}^{n=N} \phi^{c(n)}=\frac{\theta \bar{\varepsilon}}{\gamma} \cdot \frac{\frac{b}{s}\left(r^{b}-r\right)+\bar{\varepsilon} a-\frac{f}{s}}{\gamma a-\theta \bar{\varepsilon} a} .
$$

Maximizing the profit of the bank $\pi^{b}$ in (11) with respect to $b$, given the expressions of $\phi^{c}$ above and of $\phi^{b}$ in (4), one gets the arbitrage condition $r^{b}=r$ as first order condition (item 2). Given the arbitrage condition (12), expression (4) simplifies to $\phi^{b}=\frac{\bar{\varepsilon}}{\gamma}-1+\frac{b}{s}$ (item 3). Given the arbitrage condition (12), expression 26) simplifies to $\phi^{c}=(\theta \bar{\varepsilon} / \gamma) \cdot(\bar{\varepsilon}-f /(a s)) /(\gamma-\theta \bar{\varepsilon})$ (item 4). Summing $\phi^{b}$ and $\phi^{c}$ yields $\phi \equiv(\bar{\varepsilon} / \gamma) \cdot(\gamma-\theta f /(a s)) /(\gamma-\theta \bar{\varepsilon})-1+b / s$ (item 5). Using (13) and (25), one gets $N=(\ln (\bar{\varepsilon})-\ln (f /(a s))) /(\ln (\gamma)-\ln (\theta \bar{\varepsilon}))$ (item 6).

\subsection{Proof that $H(\bar{\varepsilon})$ is hump-shaped}

We want to prove that $H(\bar{\varepsilon})$ is humped-shaped over interval $[0,1]$. From the definition of $H(\bar{\varepsilon})$ in 20, , one gets:

$$
H^{\prime}(\bar{\varepsilon})>0 \Leftrightarrow\left(\frac{\gamma}{\theta}-\bar{\varepsilon}\right) \frac{\bar{\varepsilon} G^{\prime}(\bar{\varepsilon})}{1-G(\bar{\varepsilon})}<\frac{\gamma}{\theta} .
$$

Given Assumption 4, $\gamma>\theta$ and it is easy to see that the left hand side of relation (27) is equal to zero when $\bar{\varepsilon}=0$ and goes to infinity when $\bar{\varepsilon} \nearrow 1$. Therefore, $H(\bar{\varepsilon})$ reaches at least one maximum over $[0,1]$. It remains to show that this maximum is unique. To do so, we re-write (27) as:

$$
\underbrace{\frac{1}{\bar{\varepsilon}}\left(1-\frac{1-G(\bar{\varepsilon})}{\bar{\varepsilon} G^{\prime}(\bar{\varepsilon})}\right)}_{\chi(\bar{\varepsilon})}<\frac{\theta}{\gamma},
$$

and show that, under Assumption 5, $\chi^{\prime}(\bar{\varepsilon})>0: \chi^{\prime}(\bar{\varepsilon})>0 \Leftrightarrow 2 G^{\prime}(\bar{\varepsilon})+\bar{\varepsilon} G^{\prime \prime}(\bar{\varepsilon})>0$.

\subsection{Proof of Proposition 2}

The proposition compares multiple equilibria $A$ and $C$ in Figure6. The effects of the reduction in $\bar{\varepsilon}$ (item 1) so that banks use the storage technology (item 9) defines a collateral trap, as in Figure 6. As $\bar{\varepsilon}=r / a$, the interbank rate falls with $\bar{\varepsilon}$ (item 2), and from (2) and (18), it is easy to see that the spread between $r^{d}$ and $r$ go up (item 3). Item 4 results from (12). The effects of a fall in $\bar{\varepsilon}$ on outside and inside collateral (items 5 and 6 ) come directly from (13) and (14). 
The effects of a fall in the ratio of outside to inside collateral (item 7) can be seen from relation (see (13) and (15) $)\left(\phi^{b}+1-\mathbf{b} / s\right) /\left(\phi^{c}+\phi^{b}+1-\mathbf{b} / s\right)=(\gamma-\theta \bar{\varepsilon}) /(\gamma-\theta f /(a s))$ : the left hand side increases with $\phi^{b} / \phi^{c}$, and the right hand side decreases with $\bar{\varepsilon}$ and hence rises in a collateral trap. Complexity (item 8) is given by $(16)$ and this is increasing in $\bar{\varepsilon}$ and so falls. Since aggregate output increases monotonically with $\bar{\varepsilon}$ (see (24)), output, consumption, and welfare are lower (item 10). Item 11 follows from $\bar{\varepsilon}$ being reduced in a collateral trap.

\subsection{Relaxation of Assumption 1}

Assume that the creditors of a bank's subsidiary can seize all the seizable cash flows of the other subsidiaries in the group. Then, the gain of the bank if its second round subsidiaries default is equal to:

$$
\left\{\begin{array}{l}
\gamma a \phi^{c(1)} s+\max \left[b r^{b}+\bar{\varepsilon} a\left(s-b+\phi^{b} s\right)-\phi^{b} s r-\phi^{c(1)} s r ; 0\right] \\
\quad \text { if }(1-\theta) \bar{\varepsilon} a\left(s-b+\phi^{b} s\right)<\phi^{b} s r \\
\gamma a \phi^{c(1)} s+(1-\theta) \bar{\varepsilon} a\left(s-b+\phi^{b} s\right)-\phi^{b} s r \\
+\max \left[b r^{b}+\theta \bar{\varepsilon} a\left(s-b+\phi^{b} s\right)-\phi^{c(1)} s r ; 0\right], \text { otherwise. }
\end{array}\right.
$$

The comparison of (29) with the left side of (5) clearly shows that the gain from default is smaller absent Assumption 1. In the above term, we singled out the cash flows from the first round projects that can be seized by the first round lenders but not by the second round lenders, $(1-\theta) \bar{\varepsilon} a\left(s-b+\phi^{b} s\right)$. (Remember that the second round lenders can only seize a fraction $\theta$ of the first round subsidiaries' cash flows, unlike the first round lenders, who have full access to those cash flows.) If those cash flows suffice to pay the first round lenders (second line), then the bank gets the return on storage, $\gamma a \phi^{c(1)} s$, the cash flows of the first round project that are not seizable by the second round lenders, net of the repayment of the first round lenders, $(1-\theta) \bar{\varepsilon} a\left(s-b+\phi^{b} s\right)-\phi^{b} s r$, plus whatever is left after the second round lenders seized all the assets they could, $\max \left[b r^{b}+\theta \bar{\varepsilon} a\left(s-b+\phi^{b} s\right)-\phi^{c(1)} s r ; 0\right]$.

When $(1-\theta) \bar{\varepsilon} a\left(s-b+\phi^{b} s\right)<\phi^{b} s r$, in contrast, the borrowers cannot keep any cash from the first round projects. The comparison with the right side of (5) shows that the gain of the bank in default is always less than its gain when it does not default, irrespective of $\phi^{c(1)}$. This is a case where, absent Assumption 1, $\phi^{c(1)}=+\infty$ and the economy reaches the First Best. 